\title{
Shear Wave Travel Time, Amplitude, and Waveform Analysis for Earthquakes in the Kurile Slab: Constraints on Deep Slab Structure and Mantle Heterogeneity
}

\author{
SUSAN Y. SCHWARTZ AND THORNE LAY
}

\author{
Institute of Tectonics and Charles F. Richter Seismological Laboratory, University of California, Santa Cruz
}

\author{
SUSAN L. BECK
}

Department of Geosciences, University of Arizona, Tucson

\begin{abstract}
Shear wave travel times, amplitudes and broadband waveforms from 16 events in the Kurile slab are analyzed to place further constraints on the seismic velocity heterogeneity associated with the subducted oceanic lithosphere. Several previous studies have proposed that the Kurile slab penetrates into the lower mantle with little deformation other than a steepening of the dip angle, while other studies suggest that strong slab deformations occur with perhaps negligible lower mantle penetration. In an effort to detect any deep slab effects, we compare anomaly pattems covering a $60^{\circ}$ azimuthal range straddling the strike of the slab for events in three different depth intervals (>500 km, 350-500 km, and $100-200 \mathrm{~km}$ ). $S$ and $S c S$ pulse broadening is used as a measure of waveform complexity. Complexity of broadband shear waves does not vary systematically across our azimuthal range as the propagation direction changes with respect to the postulated lower mantle slab model for this region. Strong residual sphere travel time variations are found for shear waves from events at all depths; however, these variations do not display the depth dependence apparent in previous $\boldsymbol{P}$ wave analysis that has been interpreted as requiring a change in slab geometry and lower mantle penetration. The same $S$ wave residual pattem is apparent in $s S$ depth phases, and is well predicted by a recent model of shear velocity structure beneath North America. A combination of deep mantle and near-receiver aspherical structure can explain most of our observed shear wave travel time pattems, with only a minor source depth-dependent component remaining after correction. Individual amplitude and travel time measurements are poorly correlated; however, $S c S / S$ amplitude ratios and $S c S-S$ differential times are significantly correlated, consistent with geometric focussing and defocussing effects somewhere along the raypaths. The travel time behavior suggests that the responsible velocity heterogeneity is not located near the source. The absence of a strong deep slab effect on the shear waves indicates that deep slab heterogeneity is less pronounced for shear waves than expected on the basis of existing $P$ wave models derived from travel time residual sphere analysis. Various interpretations include: estimates of $\delta V_{s} / \delta T$ and compositional effects previously used to predict shear velocity structure of the deep Kurile slab are in error, with actual lower mantle slab anomalies being much weaker than proposed; the Kurile slab is so distorted in the lower mantle that no source depth dependent trends are produced for our limited focal sphere coverage; or the Kurile slab does not penetrate into the lower mantle.
\end{abstract}

\section{INTRODUCTION}

The fate of subducted oceanic lithosphere as it approaches the lower mantle is of great interest to the geophysical community. Penetration of this material below $670 \mathrm{~km}$, the maximum depth of observed seismicity, would strongly favor models of mantle convection that involve circulation of material between the upper and lower mantle over models that require two separate, upper and lower mantle convective systems. Seismological data are providing the most detailed images of the velocity gradients and depth of penetration of subducted lithosphere. Jordan [1977] proposed that subducted slabs penetrate into the lower mantle based on shear wave travel time residuals from a deep focus earthquake in the Kurile slab. He found that a vertical slab with a $5 \%$ velocity contrast striking parallel to the arc and extending to $1000 \mathrm{~km}$ in depth was consistent with his travel time data. Creager and Jordan $[1984,1986]$ subsequently analyzed compressional wave travel time residuals from several intermediate and deep focus earthquakes in the Kurile slab and after heavy smoothing of the data, found systematic patterns that were well explained by

Copyright 1991 by the American Geophysical Union.

Paper number 91JB00639.

0148-0227/91/91JB-00639\$05.00 thermal models of subducting lithosphere extending to depths of at least $1000 \mathrm{~km}$. They observed systematic differences in $P$ wave travel time patterns between deep $(>500 \mathrm{~km})$ and intermediate depth earthquakes that were modeled by a change in dip of the slab from about $50^{\circ}$ above $500 \mathrm{~km}$ to $70^{\circ}$ below this depth. Perturbing the dip by as little as $5^{\circ}$ from these optimal values significantly degraded the fit to their observed travel times. Although these $P$ wave, and much more limited $S$ wave, travel time data from the Kurile slab appear to be consistent with the presence of a tabular, fast slab extension below $670 \mathrm{~km}$, the preferred models for dip of the slab differ by about $20^{\circ}$ for the two data sets. Furthermore, the models depend strongly on several important assumptions made in the processing, particularly concerning the degree to which deep path and receiver effects have been removed.

Recently, the deep slab penetration interpretation of travel time residuals from deep focus events in the northwest Pacific has come into question. For deep earthquakes in the Marianas, Izu-Bonin, Japan, and Kurile subduction zones, Zhou et d. [1990] show that much of the observed $P$ wave travel time residual patterns, which had previously been attributed to the extension of subducted lithosphere beneath these deep events [Creager and Jordan, 1984, 1986], can be produced by diffuse heterogeneity in both the deep and near-receiver mantles. 
Although Creager and Jordan [1984, 1986] correct their travel time data using lower mantle model L02.56 [Dziewonski, 1984] and globally averaged station statics, Zhou et al. [1990] suggest that this procedure may underestimate the strength of true mantle heterogeneity and they emphasize the need for empirically derived mantle corrections prior to interpretation of travel time residual patterns. Existing aspherical models are heavily damped and poorly resolved, making their use for path specific corrections questionable. From analysis of shear wave travel time residuals from deep focus earthquakes in the northwest Pacific, Gaherty et al. [1991] also find that large scale velocity heterogeneity in the lower mantle fortuitously projects a slablike signature on shear wave travel times observed at stations along the dip direction of the Kurile slab. After application of empirically derived lower mantle corrections, they conclude that slab models substantially shorter and/or broader than those proposed by Creager and Jordan [1984, 1986] from $P$ wave analysis are more consistent with their $S$ wave observations.

In addition to travel time effects, $S$ waveform complexity observed for paths along strike of the Kurile slab has also been attributed to interactions with a tabular high velocity nearsource anomaly at depths greater than $670 \mathrm{~km}$. Silver and Chan [1986] analyzed broadband $S$ wave recordings from two deep focus events and found systematic waveform differences between $S$ and $S c S$ arrivals at several stations, which they attributed to enhanced multipathing for the direct $S$ phases caused by a lower mantle extension of the Kurile slab. This interpretation requires a steeper dipping slab than that indicated by the $P$ waves, and has not been shown to quantitatively match the data, because multipathing alone probably cannot account for the degree of relative broadening of the $S$ waves [Cormier and $\mathrm{Kim}, 1990$ ]. Direct $P$ waves at the same stations do not exhibit comparable relative broadening. Choy and Cormier [1986] provided an alternate explanation of the relative broadening of $S$ versus $S c S$ as an effect of radial variation of frequency dependent attenuation in the lower mantle. While Silver and Chan [1986] examined waveforms only along strike of the Kurile slab, Beck and Lay [1986] extended broadband $S$ wave analysis to include waveforms spanning a $100^{\circ}$ azimuth range straddling the strike of the slab. Beck and Lay [1986] found that although the largest range in waveform complexity occurred along the strike of the slab, there was no simple correlation between waveform complexity and azimuth relative to the slab strike. Observations at stations located between those used by Silver and Chan [1986] showed no anomalous broadening of the $S$ wave while some stations showed relatively broadened $S c S$ pulses. These patterns remain unexplained.

Recent developments in two and three-dimensional wave propagation techniques are making the quantification of waveform effects due to propagation through high velocity slabs possible. Vidale [1987] has shown, using a twodimensional finite difference scheme, that in addition to fast travel times, raypaths with long trajectories along a high velocity slab should produce complex waveforms with reduced amplitudes and broadened tails. The travel time and amplitude effects arise from the slab acting as an anti-waveguide, defocussing energy passing through it. The broadened waveform results from slab diffraction; the longer period energy travels in the slower material surrounding the slab and thus arrives later than the higher frequency first arrival which travels mainly within the slab [Vidale, 1987]. Cormier [1989] has computed three-dimensional Gaussian beam synthetics for wave interactions with slab structures. His synthetics for simple slab models demonstrate that slab diffraction exists over a large azimuthal range in the down-dip direction of the slab but extinguishes rapidly (within $15-20^{\circ}$ ) away from the strike of the slab in the direction opposite to the dip direction.

Cormier and Kim [1990] have used modified dynamic raytracing to predict geometric amplitude and travel time anomalies for various slab velocity models. While the correlation between predicted travel time and amplitude anomalies is complex, there are strong patterns in both anomalies which vary systematically with respect to the slab geometry. Suetsugu [1989] has attempted to establish $P$ wave amplitude and travel time anomaly patterns for deep Kurile events with paths going downdip of the slab. He found decreased short-period $\boldsymbol{P}$ wave amplitudes for rays having long paths within the lower mantle high velocity zone that he located using travel time inversion. Based on the distance range that amplitude defocussing is observed, Suetsugu [1989] favors a slab model that maintains a constant dip of $\sim 50^{\circ}$ between the depths of $250 \mathrm{~km}$ and $1200 \mathrm{~km}$, with the maximum depth of slab penetration being constrained by the travel time inversion. Gaherty et al. [1991] have compared observed shear wave amplitude and travel time anomaly patterns for deep focus events with paths in the downdip direction of the Kurile and Japan slabs with predictions for several deep slab models. Although their amplitude residuals are more scattered than the travel times, their joint interpretation of amplitude and travel time behavior has allowed them to place some constraints on the velocity structure beneath these events. Tabular slab models with high $S$ wave velocity contrasts tend to violate amplitude observations, while broadened slabs are acceptable. The data do display depth dependent trends consistent with the presence of a fairly strong slab anomaly above $670 \mathrm{~km}$, but either a weak slab anomaly or no slab anomaly below $670 \mathrm{~km}$ is consistent with the data [Gaherty et al., 1991].

It is well established that the presence of a high velocity slab in the source region should have predictable effects on the travel times, amplitudes and waveforms of raypaths encountering it. At present, very little has been done in the way of observational work on $S$ wave amplitude and travel time pattems, despite the likelihood that slab effects will be more pronounced for $S$ waves than $P$ waves due to the expected stronger effect of temperature on the shear wave velocity. The poor quality of the ISC $S$ wave travel time determinations impede the use of this catalogue in investigations of deep slab structure. Such studies require $S$ wave travel times to be manually picked from individual seismograms. The immense effort required to collect, digitize, rotate and measure shear wave arrival time and amplitudes has prevented a complete focal sphere analysis of their travel time and amplitude anomaly patterns. However, in this paper, we analyze a substantial data set of such shear wave travel times, amplitudes and waveforms recorded in a $60^{\circ}$ azimuthal range straddling the strike of the Kurile slab. We are particularly interested in evaluating whether or not the model for the Kurile slab derived from $P$ wave travel time data [Creager and Jordan, 1984, 1986] is consistent with our expanded set of shear wave observations. By examining travel times, amplitudes and waveforms together, we hope to produce more conclusive results than would be obtained through travel time analysis alone. 


\section{DATA ANALYSIS}

Table 1 lists the 16 Kurile slab events analyzed in this paper. Our data consist of transverse component $S$ and $S c S$ travel times and amplitudes for all 16 events, and broadband ground displacement records for the last four events listed in Table 1. Recording stations consist of World Wide Standardized Seismograph Network (WWSSN), Canadian Seismic Network (CSN), Regional Seismic Test Network (RSTN), and Lawrence Livermore National Laboratory Network (LLNL) stations. The event-station geometries are indicated in Figure 1. Travel times and amplitudes for ten of the events listed in Table 1 were measured by Lay [1983], who interpreted correlations in amplitude and travel time anomalies as arising from localized velocity anomalies in the lower mantle. For all events recorded at WWSSN and CSN stations, $S$ and $S c S$ travel time and amplitude measurements were made from the long-period rotated tangential seismograms. We estimate our accuracy to be $\pm 0.5 \mathrm{~s}$ and $\pm 10 \%$ in amplitude. Travel times for the RSTN and LLNL stations were read from rotated tangential broadband records; however to ensure that the amplitude measurements were made at a common frequency, the broadband displacement

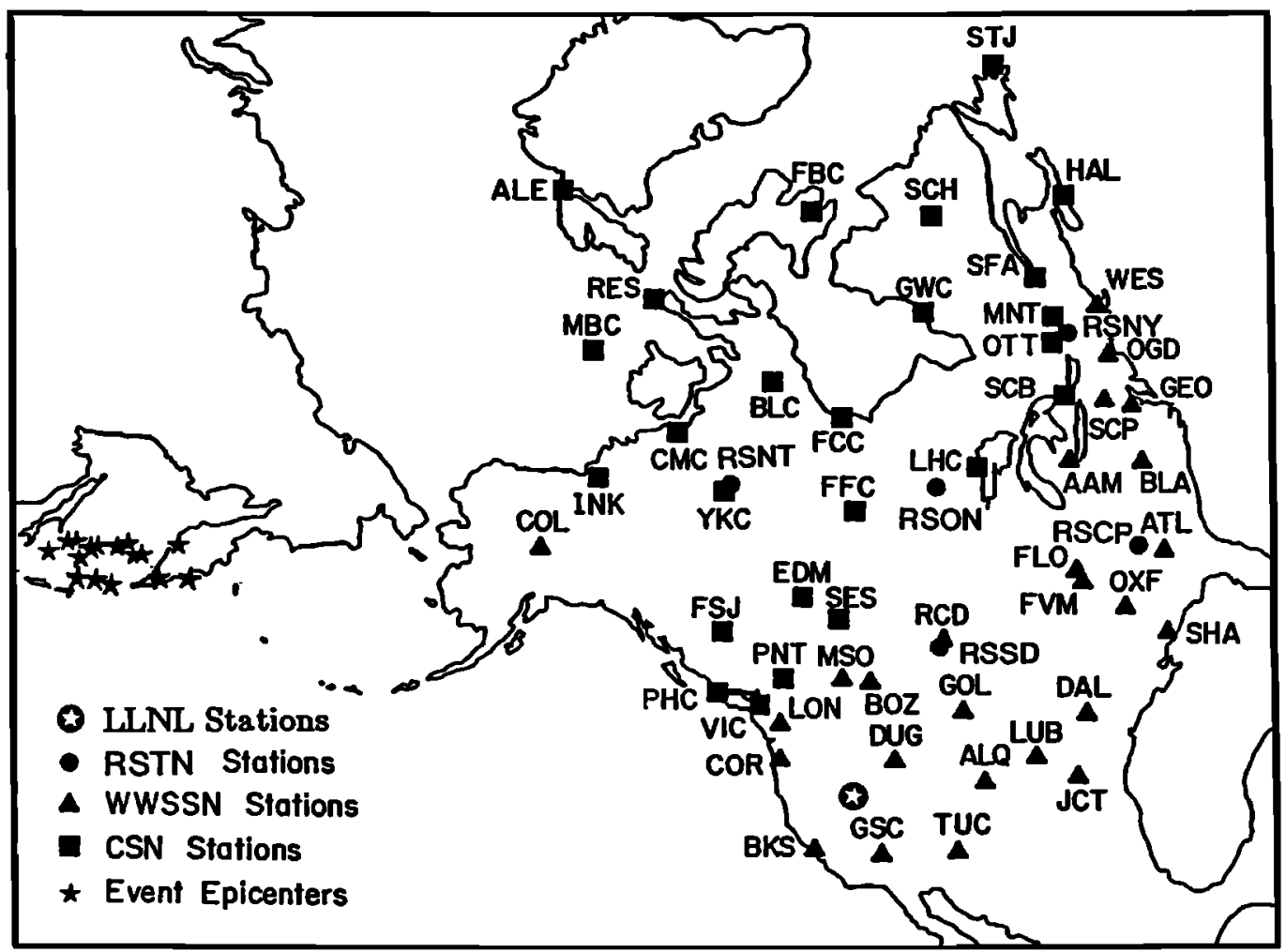

Fig. 1. Location of earhquakes (stars) and North American stations used in this study.

TABLE 1. Earhquake Source Parameters

\begin{tabular}{|c|c|c|c|c|c|c|c|c|}
\hline Date & $\begin{array}{l}\text { Origin Time } \\
\text { UT }\end{array}$ & $\begin{array}{c}\text { Lauitude } \\
\mathrm{N}\end{array}$ & $\begin{array}{c}\text { Longitude } \\
\mathrm{E}\end{array}$ & Depth, km & Strike, deg & Dip, deg & Rake, deg & Reference \\
\hline March 18, 1964* & $0437: 25.7$ & 52.56 & 153.67 & 424 & 48 & 84 & -76 & ISC,SM \\
\hline September 12,1967 & $1253: 45.9$ & 52.15 & 152.57 & 466 & 30 & 75 & -52 & ISC,IM \\
\hline December $1,1967^{*}$ & $1357: 02.4$ & 49.50 & 154.40 & 136 & 50 & 87 & 109 & NOAA,L \\
\hline September 5, 1970* & $0752: 32.4$ & 52.32 & 151.46 & 583 & 12 & 74 & -77 & $S, L$ \\
\hline January $29,1971^{*}$ & 2158:06.7 & 51.72 & 151.04 & 540 & 40 & 77 & -119 & V,SM \\
\hline May 27,1972 & $0406: 49.6$ & 54.97 & 156.33 & 397 & 25 & 82 & -93 & ISC,L \\
\hline August $21,1972^{*}$ & $0623: 48.6$ & 49.47 & 147.08 & 573 & $\overline{18}$ & 19 & 44 & ISC,L \\
\hline July 28,1973 & $2006: 35.4$ & 50.45 & 148.92 & 585 & 51 & 76 & -107 & ISC,L \\
\hline March 11, 1974 & $1137: 33.5$ & 48.32 & 153.20 & 169 & - & - & - & NEIS \\
\hline September 21, 1974 & $1554: 59.1$ & 52.19 & 157.44 & 119 & 205 & 79 & 80 & ISC,L \\
\hline July $10,1976^{*}$ & $1137: 14.0$ & 47.31 & 145.75 & 402 & 40 & 81 & -87 & ISC,L \\
\hline June $21,1978^{*}$ & $1110: 38.7$ & 48.27 & 148.60 & 380 & 286 & 27 & 12 & ISC,L \\
\hline July 24,1983 & $2307: 31.8$ & 53.91 & 158.36 & 180 & 218 & 89 & 101 & NEIC,HVD \\
\hline February 1,1984 & $0728: 28.4$ & 49.05 & 146.63 & 568 & 231 & 85 & 83 & ISC,HVD \\
\hline April 20, 1984 & $0631: 10.3$ & 50.06 & 148.77 & 578 & 257 & 16 & -74 & ISC,HVD \\
\hline July 19,1986 & 0559:35.5 & 47.24 & 151.13 & 136 & 36 & 80 & -76 & ISC,HVD \\
\hline
\end{tabular}

References for hypocentral parameters from S, Strelitz [1975]; V, Veith [1974].

References for focal mechanism parameters from IM, Isacks and Molnar [1971]; L, Lay [1983]; SM, Slawder and Mualchin [1976]; HVD.

Harvard centroid moment tensor solution.

* Events used in $s S$ and $s S C S$ travel time residual analysis 
records were convolved with the WWSSN long-period response prior to amplitude measurement.

All travel times are given as residuals relative to the PREM Earth model [Dziewonski and Anderson, 1981]. These values have been corrected for station elevation, ellipticity, and receiver structure using either the azimuthally averaged $S$ wave station corrections of Toy [1989] or Wickens and Buchbinder [1980]. All amplitude measurements are zero to peak values. $S$ and $S C S$ amplitudes have been corrected for geometric spreading predicted by PREM and source radiation terms predicted from the mechanisms listed in Table 1 except for the event on March 11,1974 , for which a focal mechanism was unavailable and amplitudes were not corrected for radiation pattern. In every case the $S H$ signals are from a stable portion of the radiation pattern so the focal mechanism correction never exceeds $30 \%$.

Broadband ground displacement records were deconvolved from the RSTN and LLNL broadband seismograms in the frequency domain applying a band-pass filter between 0.01 and $0.75 \mathrm{~Hz}$ and a cosine taper between 0.009 and $0.01 \mathrm{~Hz}$ and 0.75 and 2. Hz. Reconstituted broadband displacement records were constructed from the WWSSN and CSN short- and long-period recordings using the procedure described by Beck and Lay [1986].

\section{RESULTS}

\section{$S$ and ScS Broadband Displacement Records}

Silver and Chan [1986] have interpreted observations of anomalously broadened $S$ displacement pulses recorded at RSTN stations from two deep Kurile slab events in terms of $S$ wave multipathing in a near-source deep slab structure. While it has been demonstrated that $S$ wave velocity models of the slab may produce multipathed arrivals [Silver and Chan, 1986; Cormier, 1989], Cormier [1989] suggests that slab diffraction may be a better explanation for the broadened waveforms. Gaussian beam synthetic $S$ and $S c S$ phases, which include the effect of slab diffraction, computed for a realistic slab structure [Cormier, 1989], indicate that both $S$ and $S c S$ phases will be affected by the high velocity slab at azimuths oblique to the dip direction. Silver and Chan [1986] parameterized the $S$ wave broadening by referencing it relative to $S c S$, which they assumed to be relatively unaffected by the slab. However, the relative broadening of the $S$ wave with respect to $S c S$ is strongly dependent on the details of the slab geometry [Cormier and Kim, 1990]. Therefore, the ScS waveforms from the Kurile slab events may also be affected by the high velocity slab causing the comparison of $S$ to $S c S$ broadening to underestimate the slab effect. We analyze both $S$ and $S c S$ phases separately, in an attempt to recover a slab signature on both of these waveforms.

Our broadband displacement records come from the two deep events (February 1, 1984 and April 20, 1984) studied by Silver and Chan [1986] as well as two new intermediate depth events (July 24, 1983 and July 19, 1986) in the Kurile slab. Beck and Lay [1986] augmented Silver and Chan's [1986] observations for the two deep Kurile slab events with reconstituted broadband recordings constructed from short- and long-period WWSSN and CSN data. Here we combine both of their data sets for the two deep events with new observations from the intermediate depth events and from stations of the LLNL digital network in an analysis designed to test for systematic effects of the slab on the observed $S$ and $S c S$ waveforms. Examples of the
$S$ and $S c S$ broadband displacement pulses used in our analysis are shown in Figure 2. The displacement pulse from station FCC (Figure 2) is an example of the reconstituted broadband WWSSN and CSN data that was analyzed by Beck and Lay [1986]. The recording from MNV shows $S$ and $S c S$ displacement pulses recorded at one of the LLNL broadband stations at Mina, Nevada.

In order to consider the slab effect on both the $S$ and $S c S$ waveforms separately we parameterize waveform broadening in the manner illustrated in Figure 2. First we align the $S$ and $S c S$ displacement pulses and normalize them to a peak amplitude of unity as shown in the top panel of Figure 2. We then integrate these pulses and measure the normalized integrated area at a chosen time. We have chosen a time of $10 \mathrm{~s}$ for our measurements given that longer time intervals are increasingly corrupted by noise and receiver reverberations. Our conclusions are not very sensitive to this choice. Graphs of the normalized integrated pulse area versus time are shown in the bottom panel of Figure 2. In order to eliminate systematic differences in normalized pulse area between events arising from differences in the event source durations, we average all of the $S$ and $S c S$ values for each event and subtract the event mean from individual values. A graph of this measure of waveform broadening, in which increasing positive values indicate broader waveforms, is plotted versus the angle between the take-off direction of the ray and the plane of the slab in Figure 3. This angle was calculated assuming values for the strike and dip of the Kurile slab of strike $221^{\circ}$, dip $62^{\circ}$ for the two deep events and strike $230^{\circ}$, dip $52^{\circ}$ for the two intermediate depth events (K. Creager, personal communication, 1991).

The graph in Figure 3 indicates broadening of the $S$ (octagons) and $S c S$ (boxes) waves at all angles from the slab. This conclusion remains valid with reasonáble perturbations to the assumed slab geometry. These observations are not consistent with simple slab models. However, as suggested by Cormier [1989], variations in slab structure along strike may obscure azimuthal trends in the waveform data. Accurate threedimensional calculations of $S$ and $S c S$ waveforms bounding the strike direction of the slab are needed before the observed waveform patterns can be completely understood. Techniques for such complex synthetics are under development.

\section{S and ScS Travel Time Residual Patterns}

Figure 4 shows $S$ and $S c S$ travel time residual patterns for the 16 events listed in Table 1 separated into the three depth intervals, greater than $500 \mathrm{~km}$ (Figure 4a), between 350 and $500 \mathrm{~km}$ (Figure 4b), and between 100 and $200 \mathrm{~km}$ (Figure $4 \mathrm{c}$ ). The plots are equal area, lower hemisphere projections with the perimeter corresponding to a take-off angle of $60^{\circ} . S$ and $S c S$ travel times were averaged for each event and the event means were subtracted from the individual residuals. Triangles represent negative residuals (fast travel times) and circles represent positive residuals (slower travel times). The range of observed residuals is quite large, over $8 \mathrm{~s}$ for some of the events. The most remarkable feature of these data is the consistency of the residual patterns between all 16 events independent of source depth; stations to the north-northeast show relatively early arrival times while stations to the eastnortheast record relatively late arrival times. Correlations between travel time residual patterns averaged for events in the three different depth intervals are all highly significant (Figure 5), emphasizing the common pattern at all source depths. The 
4-20-84 FCC Depth $590 \mathrm{~km}$
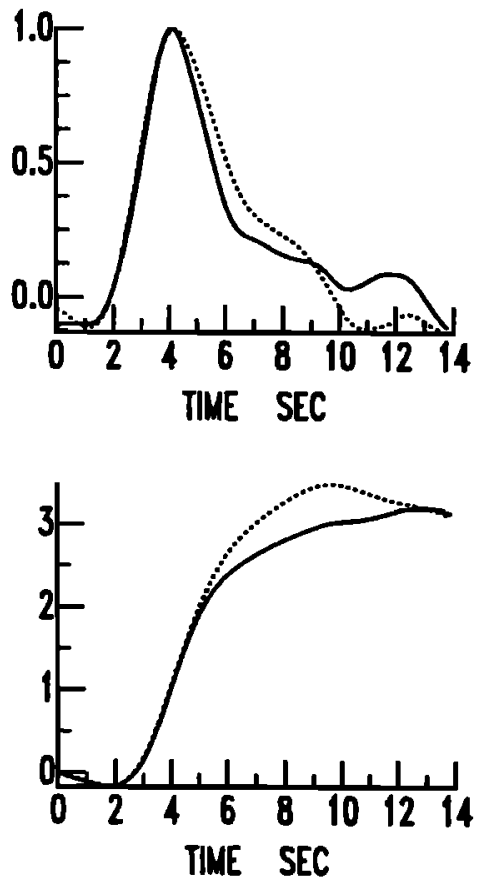

2-1-84 MN

Depth $565 \mathrm{Km}$
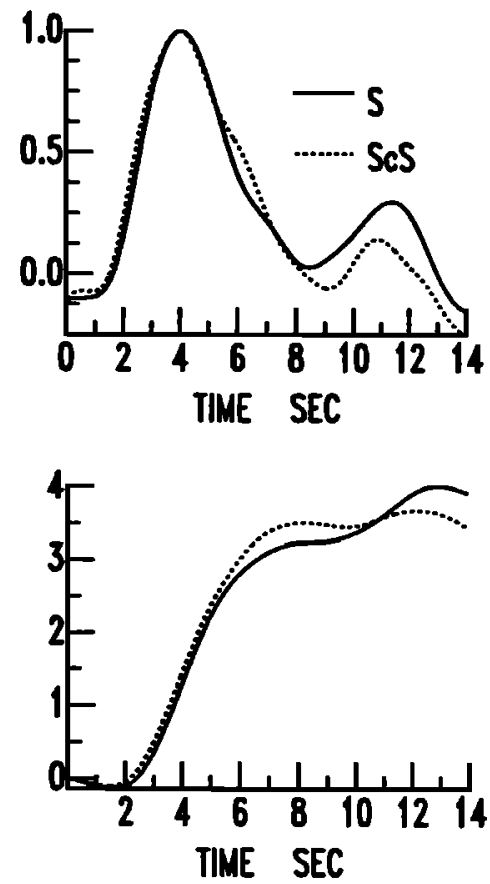

7-19-86 RSNT

Depth $136 \mathrm{Km}$
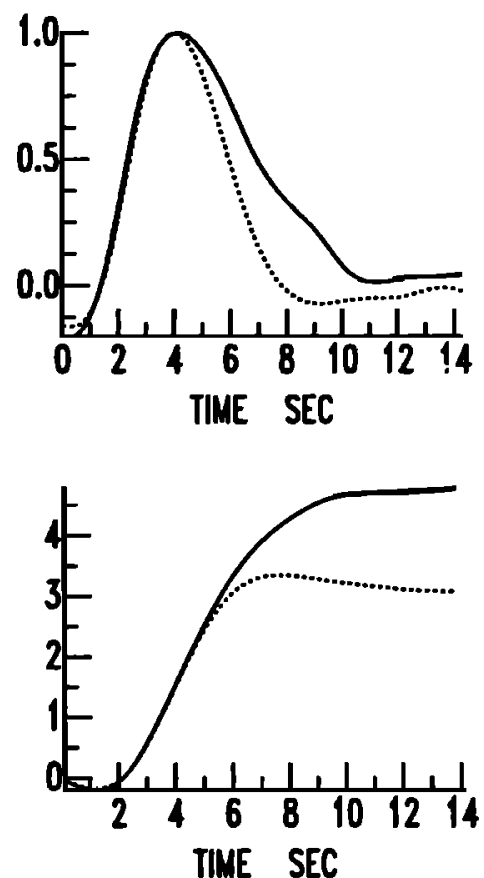

Fig. 2. Normalized $S$ and $S c S$ broadband displacement pulses (top) and their integrated curves (bottom) for three Kurile slab earthquakes. The event on April 20,1984, shows a broadened ScS relative to $S$, while the event on July 19, 1986, shows a broadened $S$ relative to $S c S$. The event on February 1, 1984, shows no relative broadening.

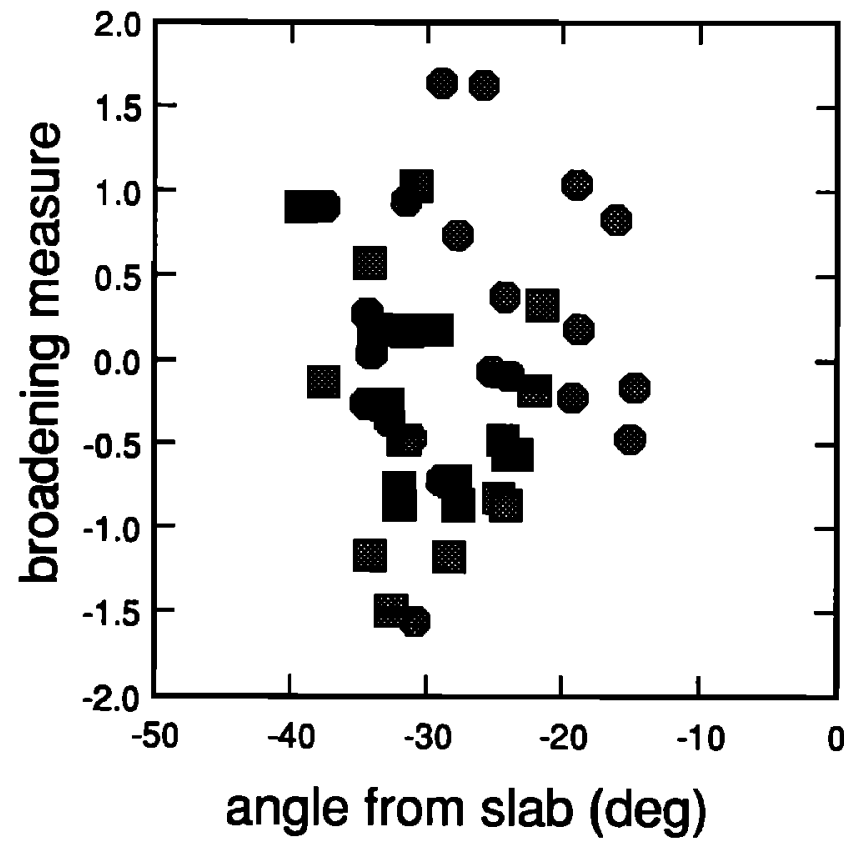

Fig. 3. Graph of normalized integrated pulse area at time $10 \mathrm{~s}$ versus the angle between the take-off direction of the ray and the plane of the slab. The boxes are ScS phases and the octagons are $S$ phases. No systematic broadening is observed relative to the slab geometry.

pattern of residuals is very similar in the corresponding azimuthal sector to that of the January 29, 1971 event studied by Jordan [1977], which he attributed to a near-source vertical high velocity slab extension. Jordan [1977] measured travel times from unrotated short-period recordings, which have higher time resolution than our long-period signals. Our relative travel time anomalies agree closely with Jordan's [1977] for the January 29, 1971 event, suggesting that travel times can be measured with high accuracy even from longperiod data, as long as they are rotated.

Because the residual travel time pattems do not change between events with very different source depths (Figure 5), explaining the common pattem by a near-source slab structure requires that it have uniform geometry over the entire depth range. The $P$ wave analysis of Creager and Jordan $[1984,1986]$ indicates that the dip of the slab in the Kurile Arc steepens below a depth of about $500 \mathrm{~km}$. Their $P$ wave travel time residual patterns change systematically as the source depth decreases [Creager and Jordan, 1984, Figure 3]; the fast travel times to the north-northeast are completely replaced with slow times as the earthquake depth nears $200 \mathrm{~km}$. Small differences between $S$ wave travel time residual patterns and $P$ wave patterns will result if $S$ wave mislocations are substantially larger than $P$ wave mislocations (K. Creager, personal communication, 1991). However, relocation produces slowly varying azimuthal patterns, and will not change the relative trend in our $S$ wave data significantly. This was also argued by Jordan [1977], who dismissed hypocentral mislocation as a significant factor contributing to his shear wave travel time residual pattems. Preliminary analysis of several shallow and deep events with complete $S$ wave azimuthal coverage (Y. Zhou and T. Lay, personal communication, 1991) shows that the strong residual trends across North America do persist for relocations in the PREM structure.

If the velocity gradients in subducted lithosphere are primarily due to the thermal structure of the slab and surrounding mantle, as modeled by Creager and Jordan [1984, 

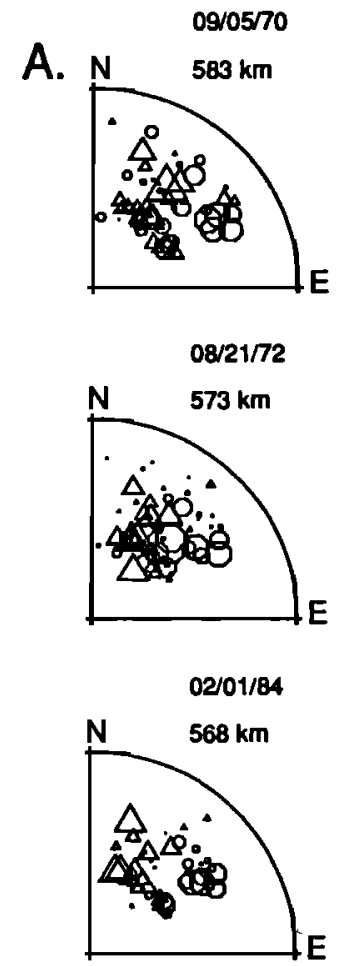

$12 / 01 / 67$

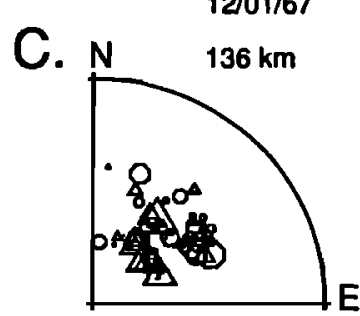

$09 / 21 / 74$

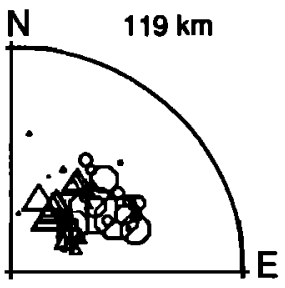

07/19/86

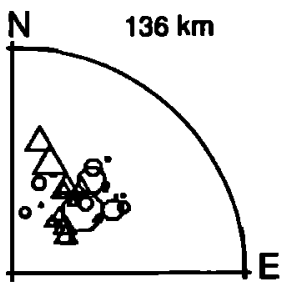

$0+3 s$

$\Delta-3 s$

Fig. 4. Demeaned shear wave travel time residuals from PREM after application of azimuthally everaged station corrections for events in the depth ranges (a) $h>500 \mathrm{~km}(b) 350<h<500 \mathrm{~km}$, and (c) $100<h<200$ $\mathrm{km}$. The residuals are plotted on lower hemisphere equal area projections with the perimeter corresponding to a take-off angle of $60^{\circ}$. The triangles represent faster than average times and the circles represent slower than average times. All events show patterns consisting of faster than average times along strike of the Kurile slab which is between $31^{\circ}$ and $50^{\circ}$ in this region.
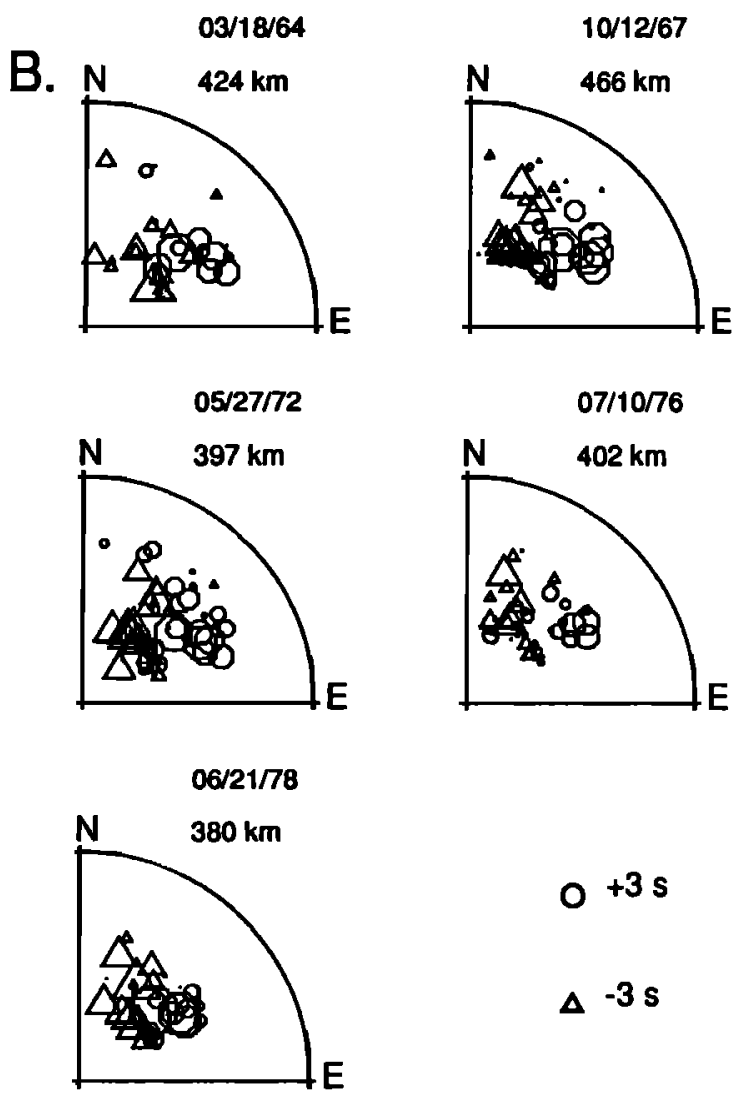

$0+3 s$

$\Delta-\mathbf{3} s$

1986], then $S$ wave travel times should be affected in the same manner but to a larger degree than the $P$ wave travel times. Estimates for $\delta V_{s} / \delta T$ computed from present values of $\delta V_{p} / \delta T$ [Creager and Jordan, 1984] assuming $\delta V_{s /} \delta V_{p}=1$ [Silver and Chan, 1986], range from -0.4 to $-0.6 \mathrm{~m} \mathrm{~s}^{-1} \mathrm{~K}^{-1}$. Since travel time anomalies are proportional to $\delta V / V^{2}$ which is larger for $S$ waves than $P$ waves, we expect the $S$ wave travel times to be more affected by slab structure than the $P$ wave travel times. The inconsistency of the shear and compressional wave travel time residual patterns suggests that our data are dominated by the effects of velocity heterogeneity at large distance from the source area that are common to all source depths. In the next sections we process the travel time data further in order to empirically strip out the effects of distant heterogeneity which may obscure any near source anomaly varying with depth.

\section{$S$ and ScS Travel Time Station Corrections}

The travel time residual patterns of Figure 4 have been corrected for azimuthally averaged station anomalies [Toy, 1989; Wickens and Buchbinder, 1980] which, to first order, should remove the effects of variable near-receiver structure. These corrections, plotted versus station azimuth from a reference event in the Kurile source region, are shown in Figure 6a. For North America, it is well established that the shear wave velocity structure beneath the Canadian shield and the eastern United States is substantially faster than the upper mantle beneath the western United States [e.g., Grand and Helmberger, 1984; Grand, 1987]. This pattem is reflected in 

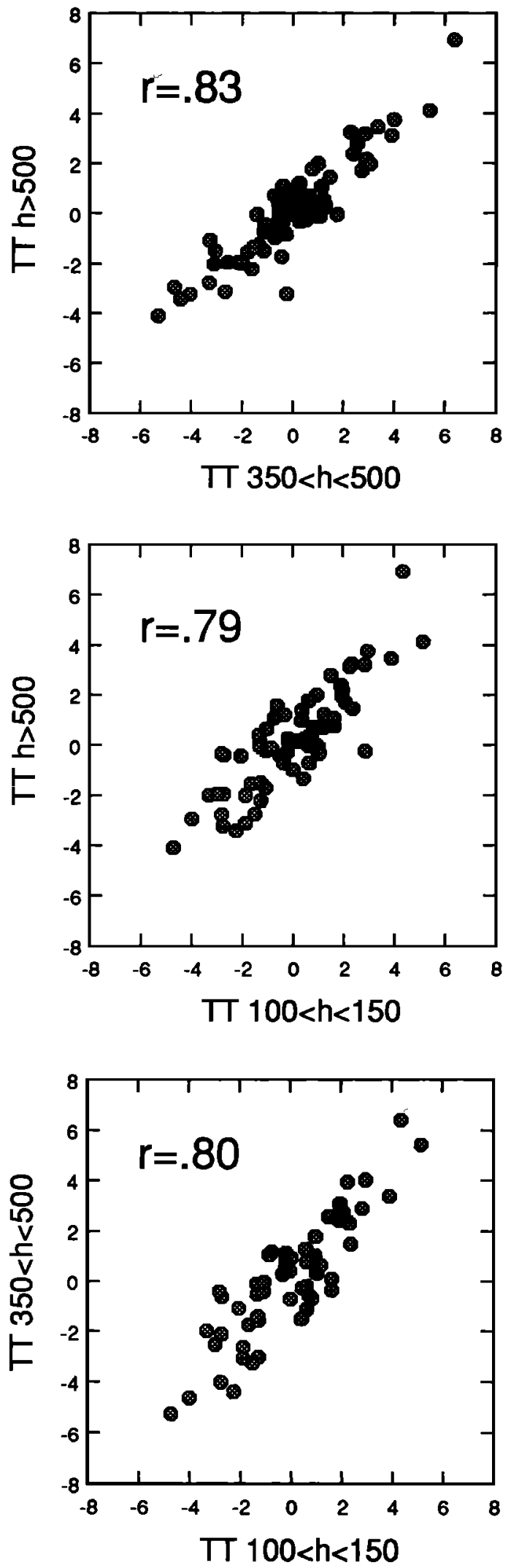

Fig. 5. Correlations between average travel time residual patterns for events in the three different depth intervals after application of azimuthally averaged station corrections. Travel time residuals (TT) are in seconds, correlation coefficients $(r)$ are high between all depth intervals.
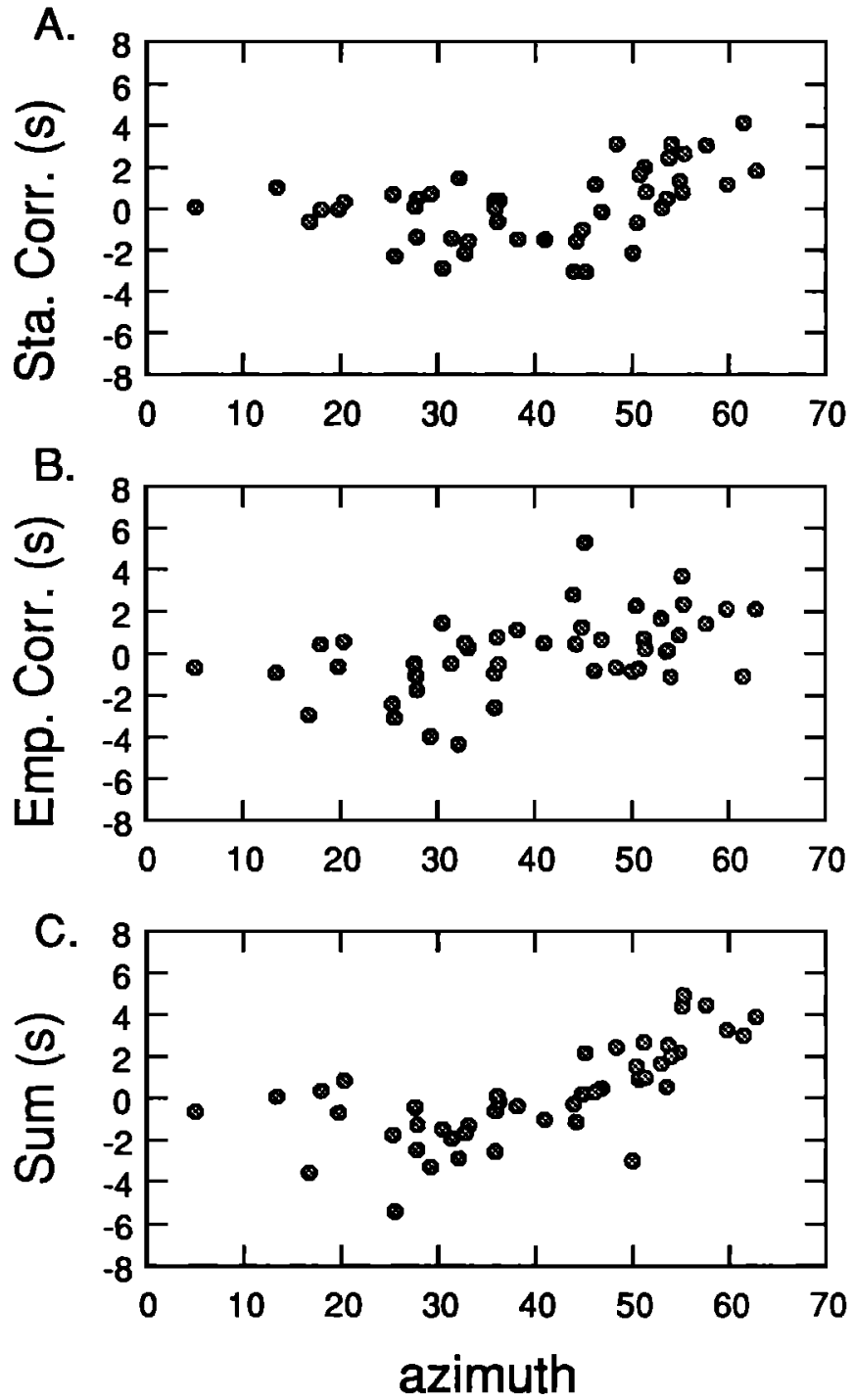

Fig. 6. (a) Plot of aximuthally averaged station corrections from Toy [1989] and Wickens and Buchbinder [1980], (b) empirically derived station corrections, and $(c)$ the sum of the above corrections versus azimuth from a refenence event. The trend of faster times to the northnortheast and slower times to the east-northeast is consistent with shear wave velocity models for the upper mantle beneath North America.

the azimuthally averaged station corrections (Figure 6a); however, the residual travel times of Figure 4 can be interpreted as still containing a component of this systematic nearreceiver bias. This could arise due to the intrinsic underprediction of station terms caused by azimuthal averaging. If strong lithospheric lateral velocity gradients exist, station corrections become essentially crustal and elevation corrections. Lay [1983], and Lay and Helmberger [1983a] have shown that very large azimuthal patterns exist in North American $S$ wave times, thus this is likely to be the case. We have attempted to remove any additional uncorrected nearreceiver heterogeneity from our travel time patterns by computing station corrections from all events in our data set. As indicated by Creager and Jordan [1984], most of the events used in this analysis have only small errors in location; however, even these small errors may introduce substantial baseline shifts in the observed travel times between the 
different events due to differences between the $S$ wave reference structure and the JB $P$ wave model used to locate the events. We have therefore computed event corrections by minimizing, in a least squares sense, the scatter in travel times at each station between events relative to a reference event. $S c S$ anomalies were treated as though they were from separate events, since we are interested in the common relative variation.

The resulting station averages, which should reflect lithospheric heterogeneity near the receivers not removed by the azimuthally averaged static terms, are plotted versus azimuth from the reference event in Figure $6 b$. The average standard error of the mean computed for the 46 stations with at least three observations is $0.37 \mathrm{~s}$. The pattern of empirically derived station corrections mimics the travel time trend we expect from known upper mantle variations in shear wave velocity. The stations located in the Canadian shield and in the eastem United States (azimuths from $0^{\circ}$ to $30^{\circ}$ ) have faster times than stations in the western United States (azimuths > $\left.40^{\circ}\right)$. This pattem is apparent in both the azimuthally averaged (Figure 6a) and empirically derived (Figure $6 b$ ) components of the station corrections and is strengthened when these terms are combined into total azimuthally dependent station corrections (Figure 6c). The total station corrections are shown on a map of North America in Figure 7, where their correlation with tectonic province is clear.

If there is no change in slab dip with depth, application of the empirically derived station corrections may actually remove a common near-source term shared by events at all depths. Analysis of many events in the same azimuth and distance range but outside the Kurile slab would be necessary to eliminate this potential tradeoff, but such a massive undertaking is beyond the scope of this paper. For the present study, the rationale for applying these additional empirical path corrections is provided by the fact that we are searching for the strong depth dependent changes in this portion of the focal sphere indicated by the $P$ waves [Creager and Jordan, 1984]. We do have one procedure for testing whether these anomalies are truly near the receivers. We compare our total station corrections with travel time residuals relative to PREM calculated using a recent, independently derived, three-

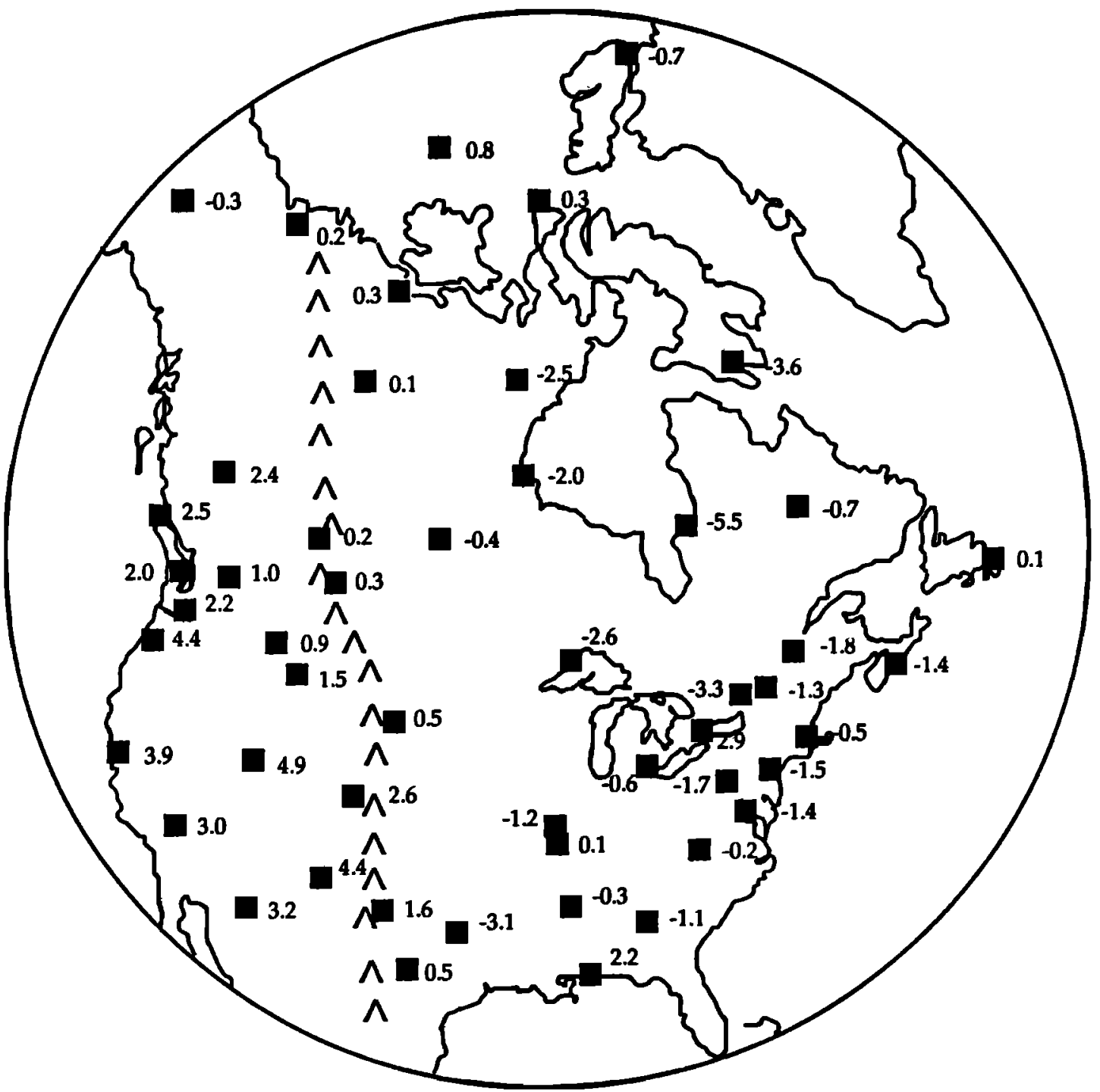

Fig. 7. Travel time station corrections (the sum of the azimuthally averaged and empirically derived corrections from Figure 6c) shown on an azimuthal equal area plot of North America. The negative values concentrate at stations located in the tectonically stable portion of North America, while the positive values concentrate at stations located west of the Rocky Mountain Front (indicated by the inverted V's). 
dimensional shear wave velocity model for the mantle under North America (S. Grand, personal communication, 1991). Figure 8 illustrates the remarkable correlation that we find, which is significant at the $99 \%$ confidence level. The correlation between our total station corrections and travel time residuals calculated using only the upper $400 \mathrm{~km}$ of Grand's model is only slightly smaller $(r=0.83)$ than the correlation using the whole mantle model ( $r=0.87$ ), suggesting that our station corrections are primarily upper mantle corrections. This is expected since both $S$ and $S c S$ were used to derive the station corrections and their paths are most similar in the upper mantle. The observed pattern spans a slightly larger range than the model predictions, indicating that at most 1-2 s of a common near-source term might be contained in the station corrections. This constitutes only $10-20 \%$ of the pattern and could also quite plausibly reflect oversmoothing of the tomographic model.

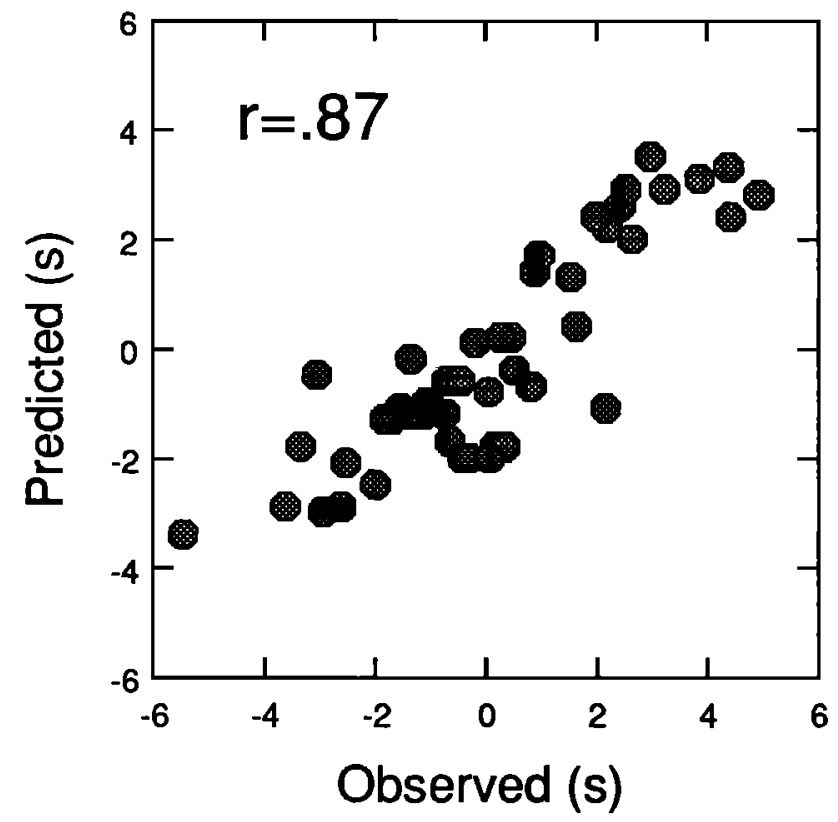

Fig. 8. Correlation between the total travel time station corrections of Figure. $6 c$ (observed) and travel time residuals relative to PREM predicted using a recent independently derived three-dimensional shear wave velocity model for North America (S. Grand, personal communication, 1991). The correlation coefficient $(r=0.87)$ indicates that this correlation is highly significant.

The travel time residuals with the total station corrections applied are plotted in Figure 9 in the same manner as in Figure 4. These travel time patterns no longer contain the common strong azimuthal trends evident in the original travel time data (Figure 4), but instead now display a clear ray parameter dependent trend. Those rays taking off steeply from the source (the $S c S$ phases) and traveling as deep as the core-mantle boundary, consistently have faster arrivals (negative residuals) relative to the shallower raypaths (the $S$ phases) which bottom at mid-mantle depths. Lay [1983] argued that ScS paths from Kurile events were systematically faster to stations in the western United States on the basis of $S c S-S$ differential travel time analysis. This trend is apparent in Figure 9 and is unlike the strong ray parameter trend predicted for stations located in the strike direction of the slab calculated by Cormier and Kim [1990] for simple near-source slab anomalies. Their calculations predict $S$ to be either as fast or faster than $S c S$ in the direction along the slab strike. The tendency for $S c S$ paths to be relatively fast is illustrated in another manner in Figure 10, where ray parameters of arrivals to a given station are averaged for events in similar depth intervals and plotted versus the corresponding averaged travel time residuals. The ray parameter trend could arise due to source depth error, common near-source structure, or systematic lower mantle velocity variations relative to PREM. Depth mislocation of Kurile slab events may result in travel time perturbations that vary smoothly with take-off angle. Relocation vectors in a homogeneous structure using teleseismic $P$ waves for Kurile slab events average about $40 \mathrm{~km}$ downward [Creager and Jordan, 1984]. Such a mislocation produces travel time perturbations that are more negative for rays taking off steeply from the source $(S c S)$ than for rays taking off more shallowly $(S)$. Therefore correction for depth mislocation could account for some of the ray parameter trend apparent in Figure 9, but depth errors of almost $80 \mathrm{~km}$ are needed to explain the $1.5 \mathrm{~s}$ trend, which is inconsistent with $s S$ and $s S c S$ anomalies for these events [Gaherty et al., 1991]. The geometry of the problem makes any interpretation in terms of a common source velocity anomaly difficult. Thus, the most likely explanation is lower mantle variation relative to PREM.

Aside from the upper $200 \mathrm{~km}$ of the Earth, the lowermost 250 $\mathrm{km}$ of the mantle (the $D^{\text {" }}$ region) is associated with the strongest lateral variations in both $P$ and $S$ wave velocities. Recent long-period models of lateral variations in lower mantle shear wave velocity [Tanimoto, 1990; Woodhouse and Dziewonski, 1987] reveal a ring of high velocities around the northem and southeastern Pacific rim in the lowermost $250 \mathrm{~km}$ of the mantle (Figure 11). The strongest gradient found in this ring of fast velocities occurs in the region beneath Alaska; ScS paths from the Kurile source region to Canadian and eastem United States stations traverse this fast $D$ " region (Figure 11). In addition, Lay and Helmberger [1983b] proposed the existence of a lower mantle shear wave velocity discontinuity with a fast $D^{\prime \prime}$ layer beneath Alaska from analysis of shear waveforms from many of the same events studied here. The high velocities in $D^{\prime \prime}$ could account for the relatively faster times of the $S c S$ phases, which travel across this region, compared to the $S$ phases, which turn in the mantle at shallower depths, where the velocities are only slightly faster than normal [Tanimoto, 1990]. Thus, large-scale lower mantle structure can produce both ray parameter and azimuthally dependent patterns. Zhou et al. [1990] investigated the contribution that velocity heterogeneity at various locations in the Earth makes to $P$ wave travel time residual patterns from events in the Kurile slab. They found that for paths along strike of the slab, the mantle model of Clayton and Comer [1983] predicts that the observations of fast arrivals in the northeast quadrant of the residual sphere come largely from fast velocities in the lower mantle. We believe that our $S$ wave travel time residuals are also contaminated by strong velocity heterogeneity in the lower mantle. Continuing toward our goal of isolating any near-source signature in the travel time data, we next empirically remove the effects of deep mantle heterogeneity from our travel time residuals.

\section{$S$ and ScS Travel Time Deep Mantle Corrections}

In order to remove the bias in our data introduced by deep mantle heterogeneity and depth mislocation, we apply a bimodal travel time correction for fast $S c S$ versus slow $S$ times 

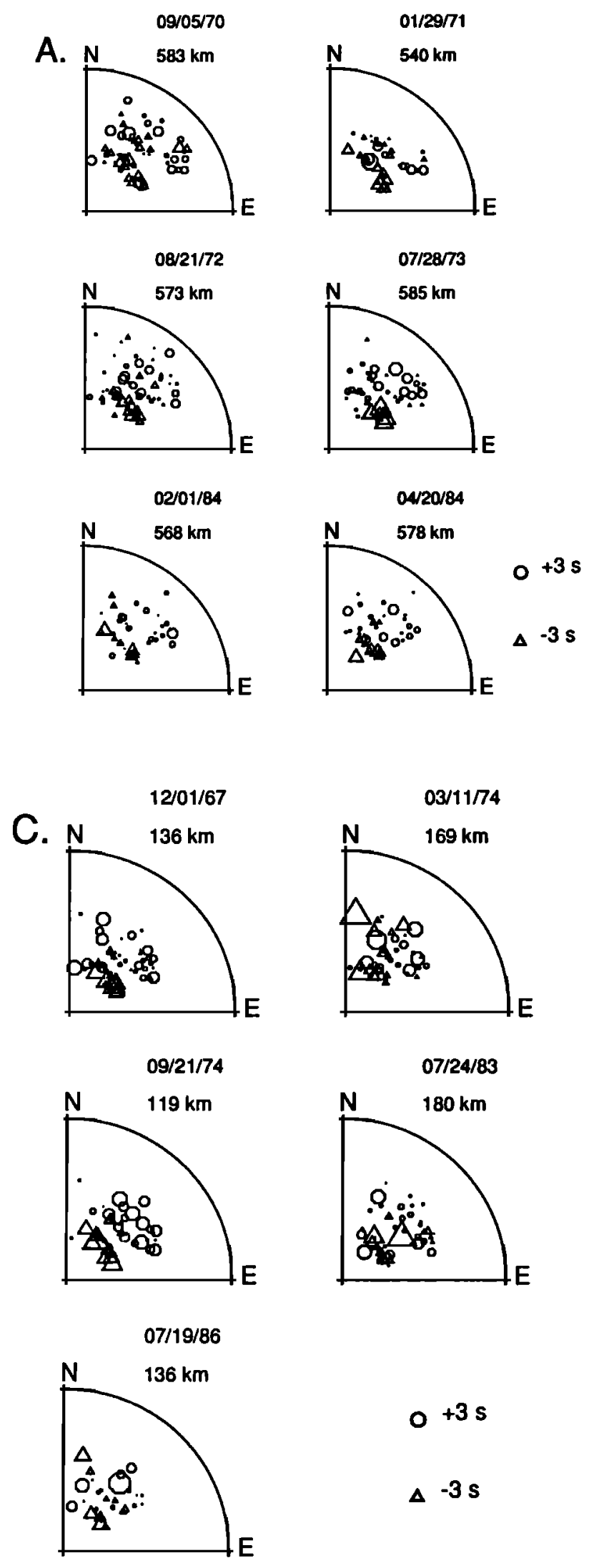

Fig. 9. Demeaned shear wave travel time residuals from PREM after application of both azimuthally averaged and empirically derived station corrections for events in the depth intervals (a) $h>500 \mathrm{~km}$, (b) $350<h<500 \mathrm{~km}$ and (c) $100<h<200 \mathrm{~km}$. The convention is the same as in Figure 4.

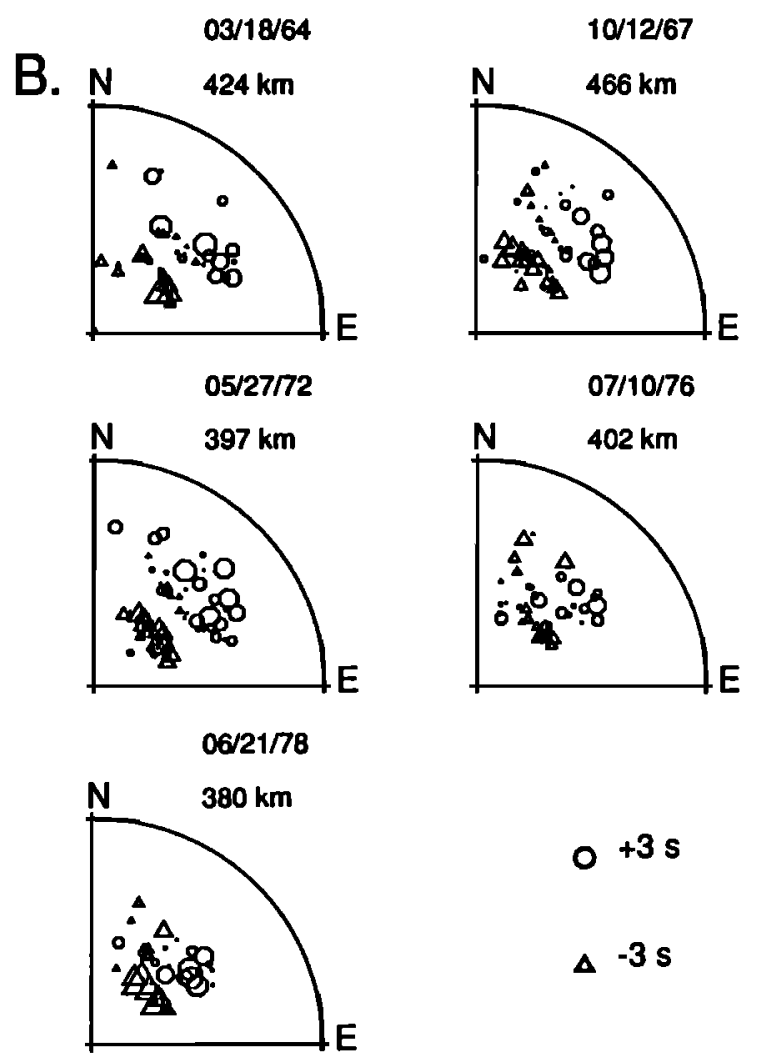

derived from Figure 10. We correct $S c S$ and $S$ travel time residuals using their average values $(-0.8 \mathrm{~s}$ and $0.7 \mathrm{~s}$ respectively) after correction for common station terms (Figure 10). Young and Lay [1990] have demonstrated that the $D^{\prime \prime}$ discontinuity beneath Alaska is relatively uniform throughout the region sampled, so a radially symmetric correction may be adequate to first order. We do not feel that the existing global lower mantle aspherical models are sufficiently reliable to provide useful path by path corrections given the strong spatial smoothing that results from low-order spherical harmonic expansions.

The pattems remaining after this final stage of processing are significantly reduced in amplitude relative to the original residual travel time patterns shown in Figure 4. The travel time residuals corrected for the ray parameter dependent trend show little systematic organization with respect to the slab, and small variation in pattern with focal depth. Figure 12 compares averaged travel time residuals for events in the three depth intervals obtained after the three stages of correction. The strong similarity in the travel time residual patterns for events in three different depth ranges after the first two stages of processing, and the lack of any coherent pattern after the third stage of processing, implies that the heterogeneity causing these pattems is common to all events within the slab and is therefore probably distant from the source region. Lay [1983] suggested that this may be the case on the basis of similarity in SCS-S differential residual patterns for shallow and deep events. Creager and Jordan [1984] were convinced that this is not the case for $\boldsymbol{P}$ waves when they observed systematic changes in $\boldsymbol{P}$ wave residuals with depth. We emphasize that our results only apply to $S$ waves.

From seismicity we know that the Kurile slab extends to a depth near $670 \mathrm{~km}$ and therefore should provide a signature in the travel time residual patterns from at least the shallowest 


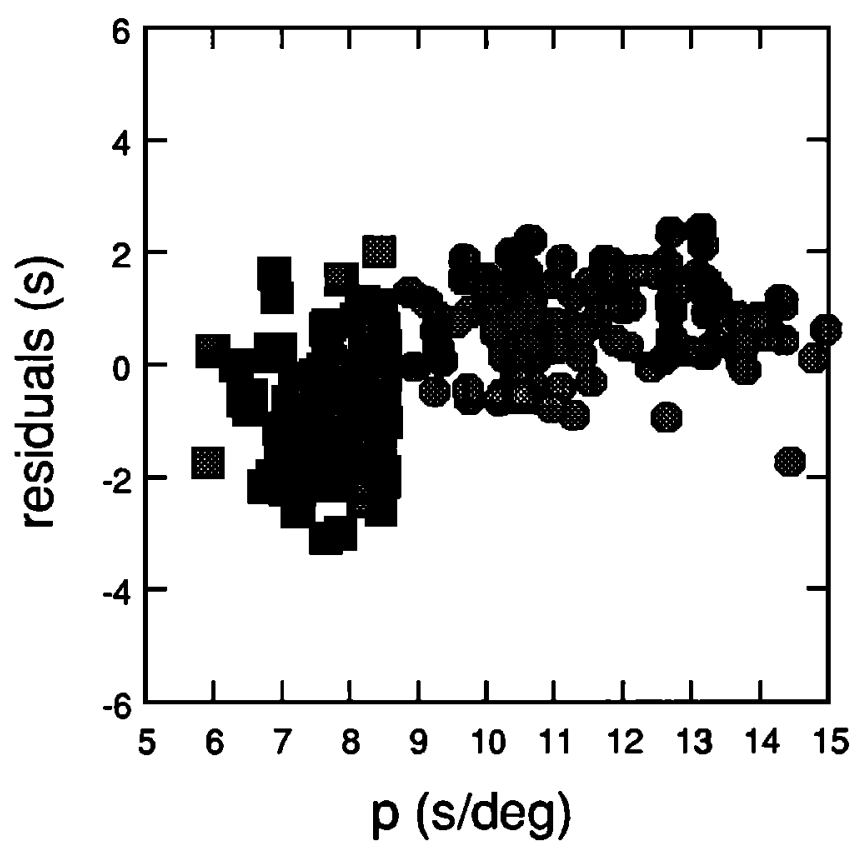

Fig. 10. Corrected travel time residuals of Figure 9 averaged for events in the three depth intervals plouted versus ray parameter. The boxes are $S c S$ phases and the octagons are $S$ phases. The $S c S$ residuals (mean-0.8 s, standard error of the mean $0.1 \mathrm{~s}$ ) are smaller than the $S$ residuals (mean $0.7 \mathrm{~s}$, standard error of the mean $.07 \mathrm{~s}$ ), consistent with a fast $D^{\prime \prime}$ region.

events. Another approach to removing common receiver and deep mantle trends from the data is to compute differential residual spheres between different depth ranges. The differenced travel time residual pattern should reflect velocity heterogeneity associated with the subducting slab. The differential residual sphere computed for the averaged deep and shallow event pattems (Figure 13) is complicated and difficult to interpret due to possible combined effects of slab structure and earthquake mislocation. There is some indication of a weak ray parameter trend in the differenced pattern, which could be a relative depth error effect. The overall pattern is much weaker than the raw residuals, suggesting relatively uniform slab contributions over the depth range. Together with the estimate of a maximum 1-2 s total common near-source term, we have the provocative inference that shear velocity anomalies of the Kurile slab are quite small, much less than the 5-10\% anomalies commonly introduced in modeling efforts to produce strong diffractions and multipathing. It is possible that thermal, compositional, and phase change effects compete, resulting in weak overall anomalies in the slab. Detailed modeling of differenced shear wave travel time residuals, covering the entire focal sphere, is required to fully understand near-source structure. Such efforts are presently under way.

Preliminary analysis of travel time residuals for the surface reflected phases $s S$ and $s S c S$ support our interpretation that much of the observed shear wave travel time residual patterns can be attributed to near-receiver heterogeneity. Figure $14 a$ shows station corrections computed using $s S$ and $s S c S$ travel times measured by Young and Lay [1990] for seven of the Kurile events listed in Table 1 . These station corrections strongly resemble the corrections derived in the same manner using the travel time residuals of the phases $S$ and $S c S$. Comparison of station corrections computed using upgoing and downgoing phases yields a comelation coefficient of $r=0.9$

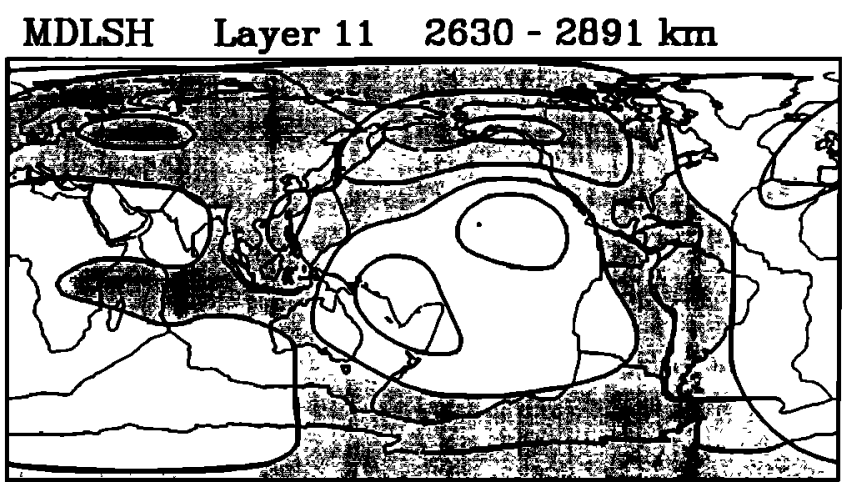

Fig. 11. Map of long-wavelength $S$ velocity anomalies in the $D^{\prime \prime}$ region determined by Tanimoto [1990]. The shaded regions are faster than PREM, and the contour interval is $0.5 \%$.

(Figure 14b), which indicates a common origin. Although upgoing phases may encounter the slab after surface reflection for paths along the strike direction, they will not spend as much time in it as their downgoing counterparts. The raypaths of upgoing and downgoing rays near the receivers are very similar and heterogeneity in this region is most likely responsible for their common travel time patterns. Thus, we again have strong empirical evidence for deep path and receiver contributions to the $S$ wave travel time patterns. Next we examine the amplitude variations in the observed $S$ and $S c S$ waveforms to ascertain if they vary systematically with respect to the slab orientation and to see if they correlate with the observed travel time patterns.

\section{$S$ and SCS Amplitude Patterns}

Since amplitudes are proportional to the second spatial derivative of velocity structure transverse to the raypath, we can anticipate that the distant velocity heterogeneities which appear to dominate the travel time patterns will have a complex effect on the amplitude data. If the heterogeneities are large scale, amplitude and travel time anomalies can be poorly correlated or decoupled. On the other hand, strong localized gradients near the source should produce fairly high correlations and systematic patterns [Cormier and Kim, 1990]. Unlike the travel time data, no published receiver terms are available to apply as first-order corrections to the amplitude data. We have computed our own amplitude receiver corrections in a manner similar to that described for the empirically derived travel time station corrections. These amplitude corrections (Figure 15), are quite scattered; however, they do show an azimuthal trend, with lower amplitudes common at the westem North American stations (azimuths $>40^{\circ}$ ) compared with the eastem North American stations. This pattern is consistent with the $20 \%$ amplitude variation expected given regional variations in attenuation of $\Delta \mathrm{t}_{\mathrm{B}}{ }^{*}=0.8 \mathrm{~s}$ beneath North America [Der et al., 1982; Lay and Helmberger, 1981, 1983a]. Thus, the primary common amplitude and travel time patterns in our data arise from coupled lateral variations in the upper mantle low velocity and low $Q$ zones between westem and eastern North America. However the correlation coefficient between the empirically derived amplitude corrections and the total travel time corrections (Figure $6 c$ ) is quite low, with $r=-0.23$. The amplitude scatter appears to obscure any correlation.

After correcting the amplitudes for the empirically derived station terms, the resulting patterns still contain too much 

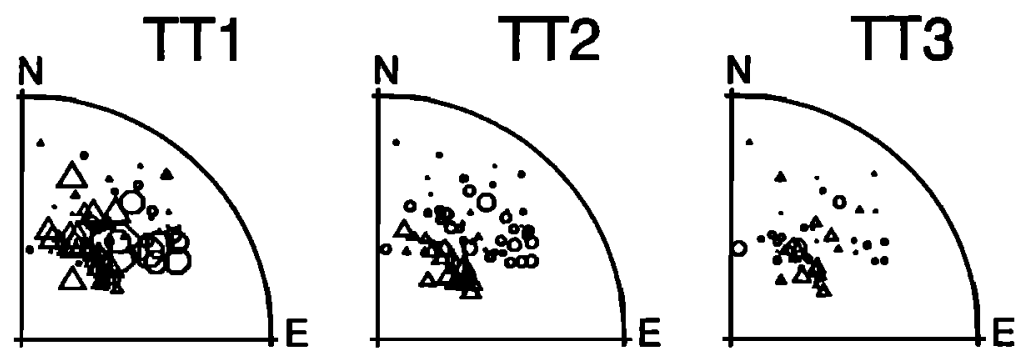

\section{$\mathrm{h}>500 \mathrm{~km}$}
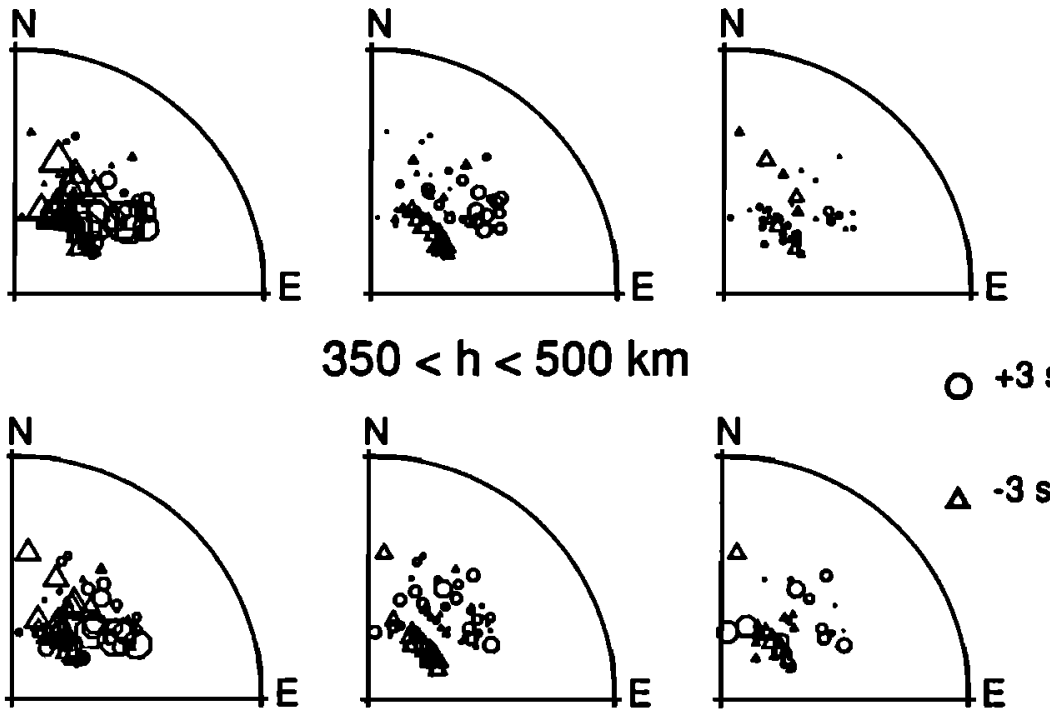

$100<\mathrm{h}<200 \mathrm{~km}$

Fig. 12. Shear wave travel time residuals averaged for events in three different depth ranges after three successive stages of correction. TT1 indicates travel time residuals with respect to PREM corrected for azimuthally averaged station terms, TT2 indicates further correction using empirically derived, azimuthally dependent, station terms, and TT3 indicates a final correction using empirically derived ray parameter dependent deep mantle terms. The residual pattems resemble one another up until the last correction regardless of earthquake source depth, suggesting that the main patterns do not result from a near-source anomaly.

\section{shallow-deep}

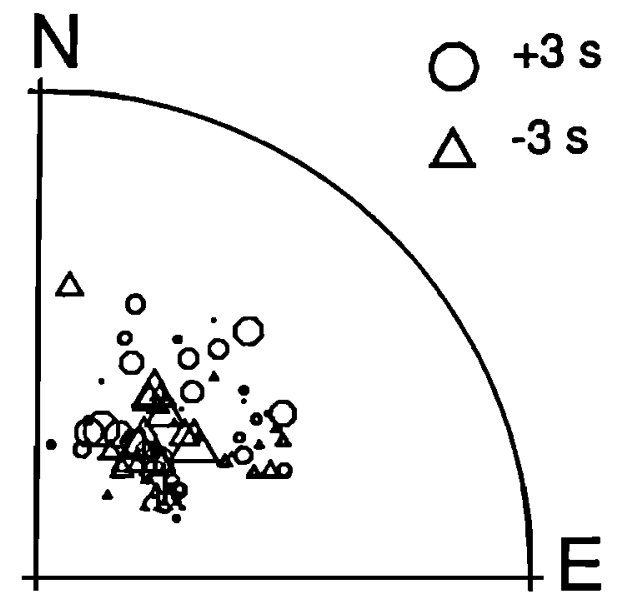

Fig. 13. Differenced shear wave travel time residuals averaged from the deepest and shallowest events after final correction (TT3 in Figure 12). The differenced pattern should reflect velocity heterogeneity associated with the slab; this pattem is quite complex. scatter to interpret in terms of simple models of velocity heterogeneity so we only consider a few of the pattems. Figure 16 shows travel time residual and amplitude patterns for the two deep focus events for which Silver and Chan [1986] examined broadband waveforms. These events have similar travel time patterns, but very different amplitude patterns. The event on February 1, 1984, shows a strong correlation between travel time and amplitude, with fast times corresponding to enhanced amplitudes. This is the pattern that Silver and Chan [1986] attributed to $S$ wave multipathing. This pattern is not representative of the remaining deep or intermediate depth events in this region, and it is not the pattern expected from a near source defocussing high velocity anomaly. The amplitude pattern of the April 20, 1984 event is not well correlated with the travel time pattern; this is true for the remainder of the events. We do not observe the simple trend of lower amplitudes along the strike direction predicted for strong slab anomalies by the calculations of Cormier and Kim [1990].

Since application of the empirically derived amplitude corrections does not reveal easily interpreted amplitude patterns, we compute the $S c S / S$ amplitude ratio and correlate it with the $S c S-S$ differential travel times from the same station. Taking ratios of amplitude measurements cancels out the effects of velocity heterogeneity or attenuation that are common to 

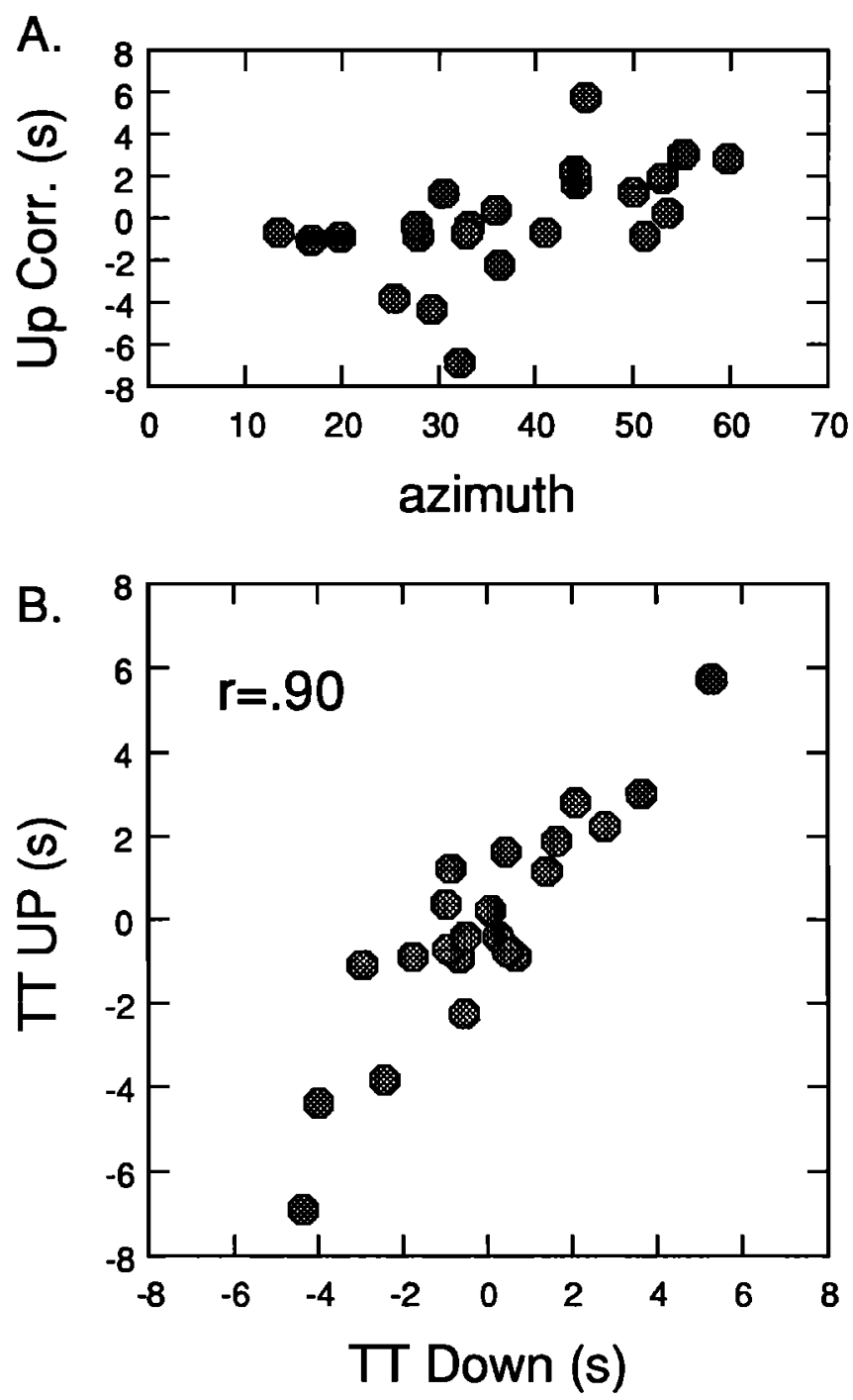

Fig. 14. (a) Empirically derived station corrections using upgoing $s S$ and $s S c S$ phases from seven Kurile slab events (average standard error of the mean $0.8 \mathrm{~s}$ ). (b) Correlation between station corrections derived using downgoing ( $S$ and $S c S$ ) and upgoing ( $s S$ and $s S C S$ ) phases. The strong correlation (correlation coefficient of 0.9 ) between station corrections implies a common source near the receivers.

both the $S$ and $S c S$ raypaths, instrument gain errors, and source rupture complexity effects that apparently contribute to the large scatter in our observations. The correlations between the amplitude ratios and differential travel times are systematically increased relative to the individual amplitude and travel time correlations at various stages of correction (Figure 17). The correlations between uncorrected travel times and amplitudes have an average correlation coefficient of 0.0 (Figure 17a). Negative correlations (i.e., fast travel times correlating with enhanced amplitudes and slow travel times correlating with diminished amplitudes) are consistent with the coupling of slow upper mantle velocities and low $Q$ regions and fast velocities and high $Q$ regions, as discussed previously, while positive correlations (i.e., fast times correlating with diminished amplitudes and slow times with enhanced amplitudes) indicate focussing effects. Correcting the travel times using the azimuthally averaged station corrections (not shown) changes the correlations very little (the average correlation coefficient becomes slightly more positive, with

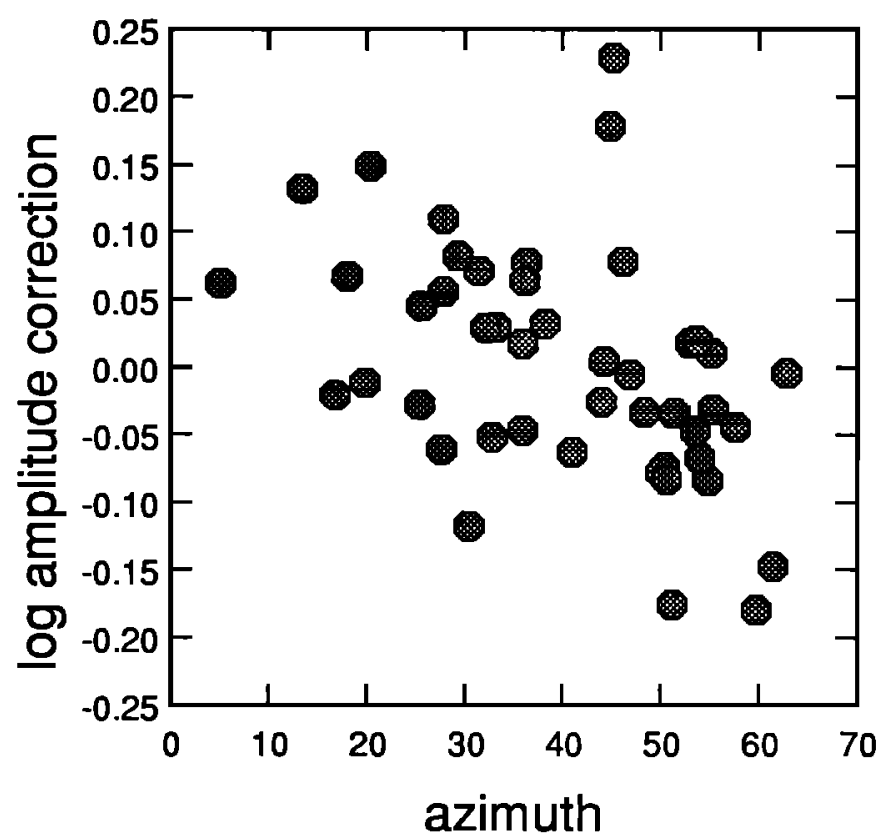

Fig. 15. Plot of empirically derived amplitude corrections versus azimuth from a reference event. The weak trend of higher amplitudes to the north-northeast and lower amplitudes to the east-northeast is consistent with models of regional variations in attenuation between westem and eastem North America. The average standard error of the mean for all observations is $0.04 \mathrm{~s}$.
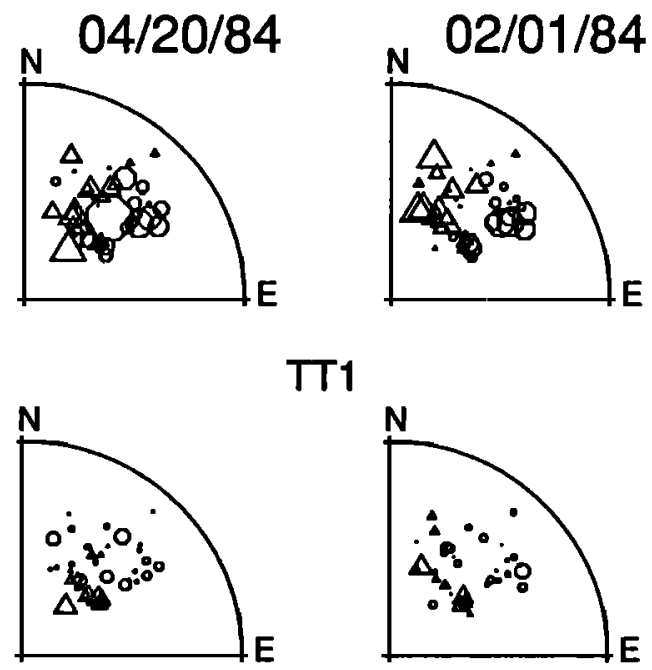

TT1
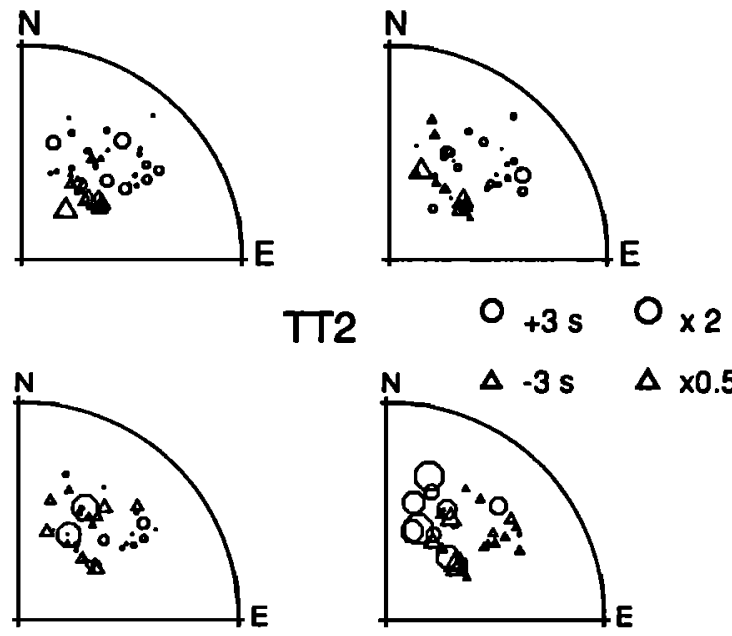

TT2

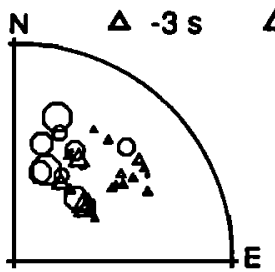

AMP

Fig. 16. Demeaned shear wave travel time and log amplitude residual patterns for two deep focus events that Silver and Chan [1986] examined for evidence of waveform broadening. TT1 and TT2 are the same as in Figure. 12. Amp indicates demeaned log amplitude residuals corrected for the empirically derived terms shown in Figure. 15. With amplitudes, triangles represent smaller than average values and circles represent larger than average values. 
A.

Uncorrected

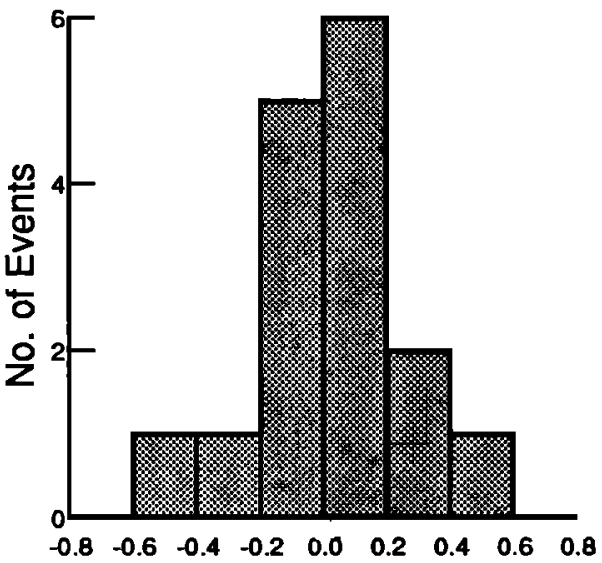

C.

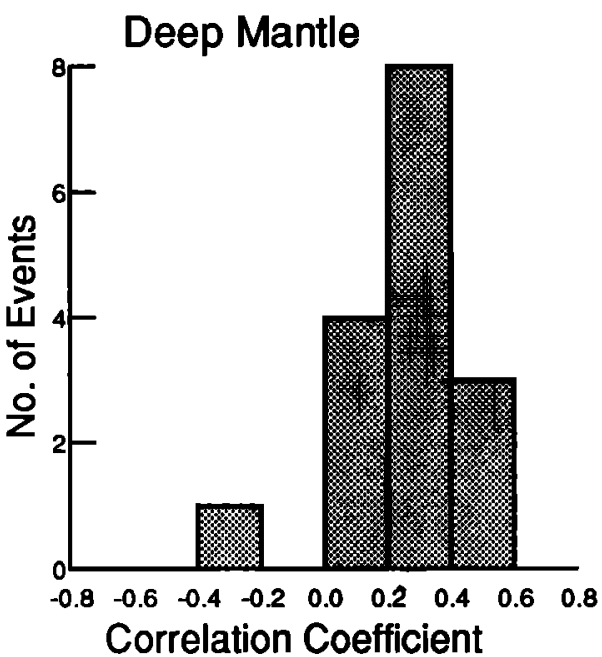

B. Station Terms

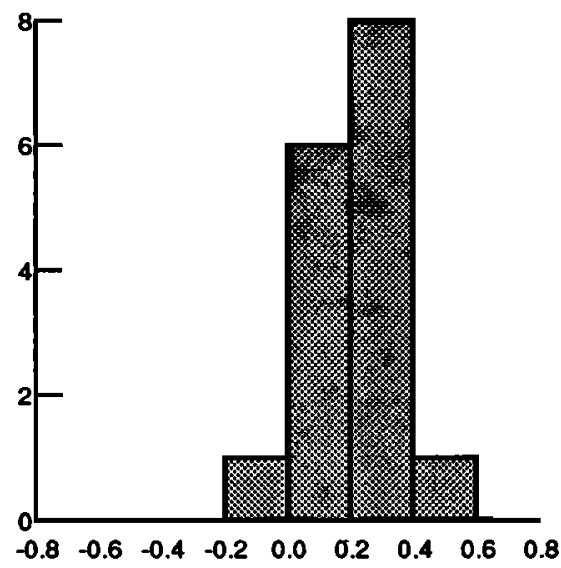

D.

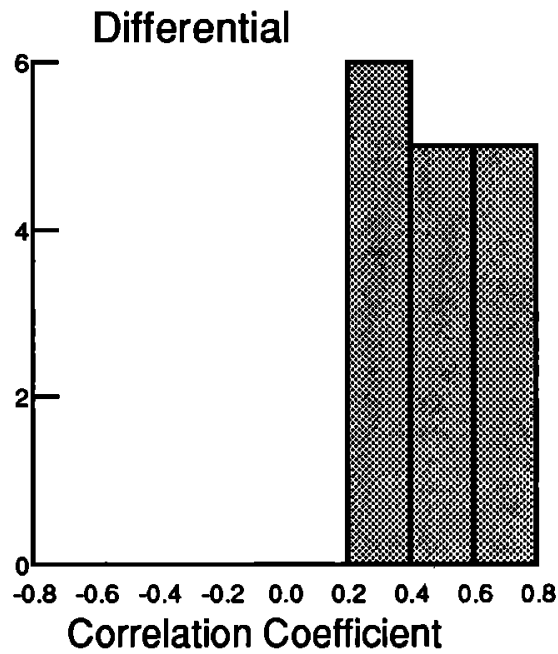

Fig. 17. Histograms of correlation coefficients resulting from the correlation of $(a)$ uncorrected amplitudes and travel times, (b) travel times and amplitudes corrected for station terms (azimuthally dependent and empirically derived terms), (c) travel times also corrected for deep mantle structure and amplitudes corrected for station terms, (d) $S c S / S$ ratios and $S c S$-S differential travel time. The differential correlations yield much higher correlation coefficients than do the correlation of individual amplitude and travel time measurements for each event.

an average value of about 0.1 ). The application of the empirically derived station corrections to both the travel time and amplitude residuals appreciably improves their correlation (Figure 17b). Travel times and amplitudes are now positively correlated for all events except the anomalous event of February 1,1984 . This positive correlation is weak with an average correlation coefficient of 0.2 , but it is now consistent with predominantly focussing and defocussing caused by velocity heterogeneity in the mantle, suggesting that the receiver lithospheric effects are indeed reduced. The correlation becomes slightly more positive (average correlation coefficient of 0.24 ) when the deep mantle induced ray parameter trend is removed from the travel times (Figure 17c). Amplitudes and travel times are still negatively correlated for the event on February 1,1984. Although there is a significant shift in the distribution of amplitude and travel time correlations from equally positive and negative to primarily positive after station statics are applied, the correlation between amplitude and travel time only becomes significant at the $95 \%$ confidence level for the differential correlations, with an average correlation coefficient of 0.48 (Figure 17d). The positive differential correlations are consistent with the existence of a high velocity defocussing (relatively fast $S$ or $S c S$ times and relatively diminished $S$ or $S c S$ amplitudes) or a low velocity focussing (relatively slow $S$ or $S c S$ times with enhanced $S$ or $S c S$ amplitudes) anomaly somewhere along the $S$ or $S c S$ raypath. Although differential measurements do not indicate which model is best or which phase is focussed or defocussed, a fast $D$ " layer with a velocity gradient that slightly decreases $S c S$ amplitudes is a plausible model consistent with other observations [Young and Lay, 1990].

\section{DISCUSSION AND CONCLUSION}

Cross-sections of seismicity in the northem section of the Kurile Arc indicate a change in slab dip from $\sim 50^{\circ}$ to $\sim 70^{\circ}-90^{\circ}$ somewhere near $500 \mathrm{~km}$ depth while cross-sections in the central and southern sections indicate a constant dip of about $50^{\circ}$ [Veith, 1974]. The geometry of the northern Kurile slab should produce differences between $S$ wave travel time residual patterns from sources located in the shallowly and more steeply dipping portions of the slab, as has been observed in $P$ wave 
travel time residuals from this region [Creager and Jordan, 1984]. Based only on seismicity, we might not expect this change to occur in the central and southem portions of the slab. In this paper we evaluate the consistency of our data with the model for the Kurile slab derived from $P$ wave travel time data. Thus, the absence of a clear source depth dependence on the $S$ wave travel time residual patterns presented here is somewhat surprising. As mentioned previously, if $S$ wave mislocation is substantially greater than the $P$ wave mislocation, $S$ and $P$ wave residual travel time patterns may differ somewhat from one another. Predicted $S$ wave travel time residuals for deep and intermediate depth events in the Kurile Arc, using relocated $\boldsymbol{P}$ wave residuals calculated for the slab model of Creager and Jordan [1984] and some reasonable assumptions about $P$ to $S$ scaling, indicate that theoretical $S$ and $P$ wave residual travel time patterns for shallow events may be expected to differ slightly from one another (K. Creager, personal communication, 1991). However, our observed $S$ wave residual patterns do not strongly resemble those derived from $P$ waves, suggesting that $S$ wave mislocation may not greatly exceed $P$ wave mislocation and that differences between our observations and those of Creager and Jordan [1984] must be attributed to other factors.

We have argued that strong shear wave heterogeneity in both the upper mantle beneath North America and in the deepest mantle ( $\left.D^{\prime \prime}\right)$ beneath Alaska dominates any near source contribution to the shear wave travel time patterns. Comparable $P$ wave heterogeneity has also been suggested as contaminating the compressional wave travel time residual patterns [Zhou et al., 1990]. Improved global threedimensional velocity models are necessary to correct travel time data for propagation effects before shear wave residual patterns can be confidently interpreted in terms of near source velocity heterogeneity. Other explanations for the inconsistency between the observed $S$ and $P$ wave travel time patterns seem less plausible but a few are briefly considered here.

1. Seismic anisotropy: $\boldsymbol{P}$ wave anisotropy is expected to be stronger than $S$ wave anisotropy at shallow depths in oceanic lithosphere where olivine and orthopyroxene are stable [Christensen and Salisbury, 1979]. Little is known about $P$ and $S$ wave anisotropy below this depth and it is conceivable that differences in the magnitude and/or orientation of $P$ and $S$ wave anisotropy might produce differences in their travel time patterns that vary with depth.

2. Differences in data processing: The processing of the $\boldsymbol{P}$ wave travel time data [Creager and Jordan, 1984, 1986] is very different from the methods used in this $S$ wave analysis. However, the Kurile slab model derived from $S$ wave travel time data [Jordan, 1977] processed in a similar manner to the $P$ wave data has a substantially steeper dip below $500 \mathrm{~km}$ than is bestfit by the $P$ wave data [Creager and Jordan, 1984]. This discrepancy indicates that factors other then differences in data processing are responsible for inconsistencies in the $S$ and $P$ wave travel time data. We suggest that this is primarily the result of path anomalies well removed from the source region which were incompletely removed by Jordan's [1977] processing. There may be a complex relationship between $P$ and $S$ corrections, thus empirical approaches appear to be needed at present.

Our analysis of shear wave travel times, amplitudes and waveforms along strike of the Kurile Arc to search for the effects of a deep slab extension has revealed the following: waveform complexity for broadband $S$ wavès is not systematically organized with respect to postulated deep slab structure; $S$ wave travel time residuals for Kurile events spanning source depths between 100 and $600 \mathrm{~km}$ show similar patterns across North America, independent of their source depth; a combination of deep mantle and near-receiver structure can explain much of the $S$ wave travel time patterns; $S$ and $S c S$ amplitude and travel time patterns are not well correlated; however, $S c S / S$ amplitude ratios and $S c S-S$ differential travel times show a rather high positive correlation. All of these conclusions strongly indicate that slab heterogeneity is less pronounced for $S$ waves than expected assuming slab geometries derived from previous $P$ wave studies. Clearly if slab velocity anomalies associated with lower mantle slab extensions are small and diffuse, seismological techniques will be hard pressed to demonstrate the extent of slab penetration. This study supports several recent analyses of $P$ waves that indicate near-source and lower mantle slab heterogeneity may have been over predicted by earlier residual sphere analyses. Additional work, with independently constrained path corrections, is required before a definitive resolution of the depth of slab penetration will be achieved.

Acknowledgments. We thank Zhengyu $\mathrm{Xu}$ for help digitizing seismograms, John Vidale and Justin Revenaugh for useful comments on the manuscript, Ken Creager for calculation of theoretical $P$ and $S$ wave travel time residual patterns and a thorough review, and Steve Grand for his computation of travel time residuals expected using his recent shear wave velocity model. This work was partially supponted by the University of Califomia President's Fellowship Program (S.Y.S.), Institute of Geophysics and Planetary Physics-Lawrence Livermore National Laboratory grant \# 90-21(SYS and SLB), NSF grant EAR8451715 (TL), and a grant from the W.M. Keck Foundation. Institute of Tectonics and C.F. Richter Seismological Laboratory, U.C. Santa Cruz, contribution 113.

\section{REFERENCES}

Beck, S.L., and T. Lay, Test of the lower mantle slab penetration hypothesis using broadband $S$ waves, Geophys. Res. Lett., 13, 1007 1010. 1986.

Choy, G.L. and V.F. Cormier, Direct measurement of the mantle attenuation operator from broadband $P$ and $S$ waveforms, $J$. Geophys. Res., 91, 7326-7342, 1986.

Christensen, N.I., and M.H. Salisbury, Seismic anisotropy in the oceanic upper mantle: Evidence form the Bay of Islands ophiolite complex, J. Geophys. Res., 84, 4601-4610, 1979.

Clayton, R.W., and R.P. Comer, A tomographic analysis of mantle heterogeneities from body wave travel times, Eos Trans. $A G U, 64$, 776, 1983.

Cormier, V.F., Slab diffraction of $S$ waves, J. Geophys. Res., 94 , 3006-3024, 1989.

Cormier, V.F., and W. Kim, Three-dimensional modeling of subducted lithospheric slabs from the amplitudes and waveforms of $\mathbf{S}$ waves, Effects of a descending lithospheric slab on yield estimates of Aleutian Nuclear Tests, Geophys. Lab. Tech. Rep. GL-TR-90-0154, USAF, Hanscom AFB, MA, 1990.

Creager, K.C., and T.H. Jordan, Slab penetration into the lower mantle, J. Geophys. Res., 89, 3031-3049, 1984.

Creager, K.C., and T.H. Jordan, Slab penetration into the lower mantle beneath the Mariana and other island arcs of the northwest Pacific, $J$. Geophys. Res., 91, 3573-3589, 1986.

Der, Z.A., T.W. McElfresh, and A. O'Donnell, An investigation of the regional variations and frequency dependence of anelastic attenuation in the manlle under the United States in the $0.5-4 \mathrm{~Hz}$ band, Geophys. J. R. Astron. Soc., 69, 67-100, 1982.

Dziewonski, A.M., Mapping the lower mantle: determination of lateral heterogeneity in $P$ velocity up to degree and order $6, J$, Geophys. Res., 89, 5929-5952, 1984.

Dziewonski, A.M., and D.L. Anderson, Preliminary reference Earth model, Phys. Earth Planet. Inter., 25, 297-356, 1981. 
Gaherty, J., T. Lay, and J. Vidale, Investigation of deep slab structure using long-period $S$ waves, J. Geophys. Res., in press, 1991.

Grand, S., Tomographic inversion for shear velocity beneath the North American plate, J. Geophys. Res., 92, 14,065-14,090, 1987.

Grand; S., and D. Helmberger, Upper mantle shear velocity structure of North America, Geophys. J. R. Astron. Soc., 76, 399-438, 1984.

Isacks, B., and P. Molnar, Distribution of stresses in the descending lithosphere from a global survey of focal-mechanism solutions of mantle earthquakes, Rev. Geophys., 9, 103-174, 1971.

Jordan, T.H., Lithospheric slab penetration into the lower mantle beneath the Sea of Okhotsk, J. Geophys., 43, 473-496, 1977.

Lay, T., Localized velocity anomalies in the lower mantle, Geophys. $J$. $R$. Astron. Soc., 72, 483-516, 1983.

Lay, T., and D.V. Helmberger, Body wave amplitude pattems and upper mantle attenuation variations across North America, Geophys. J. $R$. Astron. Soc., 66, 691-726, 1981.

Lay, T., and D.V. Helmberger, Body wave amplitude and travel time correlations across North America, Bull. Seismol. Soc. Am., 73, 1063-1076, 1983a.

Lay, T., and D.V. Helmberger, A lower mantle triplication and the shear velocity structure of $D^{\prime \prime}$, Geophys. J. R. Astron. Soc., 75, 799-838, $1983 b$.

Silver, P.G., and W.W. Chan, Observations of body wave multipathing from broadband seismograms: Evidence for lower mantle slab penetration beneath the Sea of Okhotsk, J. Geophys. Res., 91, 13,787-13,802, 1986.

Stauder,W., and L. Mualchin, Fault motion in the larger earthquakes of the Kurile-Kamchatka arc and of the Kurile-Hokkaido comer, $J$. Geophys. Res., 81, 297-308, 1976.

Strelitz, R., The September 5, 1970 Sea of Okhotsk earthquake: a multiple event with evidence of triggering, Geophys. Res. Lett., 2, 124-127, 1975.

Suetsugu, D., Lower mantle high velocity zone beneath the Kurils as inferred from $P$ wave travel time and amplitude data, J. Phys. Earth, 37, 265-295, 1989.

Tanimoto, T., Long wavelength $S$ wave velocity structure throughout the mantle, Geophys. J. Int., 100, 327-336, 1990.

Toy, K.M., Tomographic analysis of ISC travel time data for earth structure, Ph.D. thesis, Scripps Inst. of Oceanogr., La Jolla, Calif., 1989.

Veith, K.F., The relationship of island arc seismicity to plate tectonics, Ph.D. thesis, Southem Methodist Univ., Dallas, Tex.,1974.

Vidale, J.E., Waveform effects of a high velocity, subducted slab, Geophys. Res. Lett., 14, 542-545, 1987.

Wickens, A.J., and G.G.R. Buchbinder, $S$-wave residuals in Canada, Bull. Seismol. Soc. Am., 70, 809-822, 1980.

Woodhouse, J.H., and A.M. Dziewonski, Models of the upper and lower mantle from waveforms of mantle waves and body waves, Eos Trans. $A G U, 68,356,1987$.

Young, C., and T. Lay, Multiple phase analysis of the shear velocity structure in the $D^{\prime \prime}$ region beneath Alaska, J. Geophys. Res., 95, 17,385-17,402, 1990.

Zhou, H.-W., D.L. Anderson, and R. W. Clayton, Modeling of residual spheres for subduction zone earthquakes, 1. Apparent slab penetration signatures in the NW Pacific caused by deep diffuse mantle anomalies, J. Geophys Res., 95, 6799-6827, 1990.

S.L. Beck, Department of Geosciences, University of Arizona, Tucson, AZ 85721.

T. Lay and S.Y. Schwartz, Institute of Tectonics and Charles F. Richter Seismological Laboratory, University of California, Santa Cruz, CA 95064.

(Received October 12, 1990; revised February 28, 1991; accepted February 28, 1991.) 